\title{
1 REAP: A platform to identify autoantibodies that target the human exoproteome
}

3 Eric Y. Wang ${ }^{1, *}$, Yile Dai ${ }^{1,{ }^{*}}$, Connor E. Rosen ${ }^{1, *}$, Monica M. Schmitt ${ }^{4}$, Mei X. Dong ${ }^{3}$, Elise

4 M. N. Ferré ${ }^{4}$, Feimei Liu ${ }^{1}$, Yi Yang ${ }^{1}$, Jaime A. Gonzalez-Hernandez¹, Eric Meffre ${ }^{1}$,

5 Monique Hinchcliffe ${ }^{3}$, Fotios Koumpouras ${ }^{3}$, Michail S. Lionakis ${ }^{4}$, Aaron M. Ring ${ }^{1,2, \#}$

6

$7{ }^{1}$ Department of Immunobiology, Yale School of Medicine, New Haven, CT, USA

82 Department of Pharmacology, Yale School of Medicine, New Haven, CT, USA

$9{ }^{3}$ Department of Internal Medicine, Yale School of Medicine, New Haven, CT, USA

$10{ }^{4}$ Fungal Pathogenesis Section, Laboratory of Clinical Immunology and Microbiology,

11 National Institute of Allergy \& Infectious Diseases, National Institutes of Health,

12 Bethesda, MD, USA.

13

14 * These authors contributed equally to this work

15 \# Correspondence: aaron.ring@yale.edu (A.M.R.) 


\section{Abstract}

33 Autoantibodies that recognize extracellular proteins (the "exoproteome") exert potent

34 biological effects but have proven challenging to detect with existing screening

35 technologies. Here, we developed Rapid Extracellular Antigen Profiling (REAP) as a

36 technique for comprehensive, high-throughput discovery of exoproteome-targeting

37 autoantibodies. With REAP, patient samples are applied to a genetically-barcoded library

38 containing 2,688 human extracellular proteins displayed on the surface of yeast.

39 Antibody-coated cells are isolated by magnetic selection and deep sequencing of their

40 barcodes is used to identify the displayed antigens. To benchmark the performance of

41 REAP, we screened 77 patients with autoimmune polyendocrinopathy candidiasis

42 ectodermal dystrophy (APECED). REAP sensitively and specifically detected known

43 autoantibody reactivities in APECED in addition to numerous previously unidentified

44 reactivities. We further screened 106 patients with systemic lupus erythematosus (SLE)

45 and identified novel autoantibody reactivities against a diverse set of antigens including

46 growth factors, extracellular matrix components, cytokines, and immunomodulatory

47 proteins. Several of these responses were associated with disease severity and specific

48 clinical manifestations of SLE and exerted potent functional effects on cell signaling ex

49 vivo. These findings demonstrate the utility of REAP to atlas the expansive landscape of

50 exoproteome-targeting autoantibodies and their impacts on patient health outcomes. 


\section{Introduction}

65 Autoantibodies play a major etiological role across a wide range of diseases spanning

66 autoimmunity, cancer, metabolic dysfunction, cardiovascular disease, infectious

67 diseases, and even neurological and neurodegenerative conditions ${ }^{1-8}$. Though

68 autoantibodies are commonly associated with adverse effects, they can also exhibit

69 disease-ameliorating functions that are beneficial to patients. For example,

70 immunosuppressive anti-cytokine autoantibodies are associated with less severe disease

71 in numerous autoimmune conditions ${ }^{9,10}$; similarly, anti-tumor specific and opsonizing

72 antibodies are associated with better survival in cancer patients ${ }^{11-13}$. Thus, analogous to

73 genetic mutations, autoantibodies may explain a significant fraction of the clinical and

74 phenotypic variation seen between individuals. Discovery of novel functional

75 autoantibody responses in patients therefore has the potential to uncover key etiologic

76 factors and therapeutic targets similar to the study of human genetics.

78 Within the human proteome, a particularly important group of autoantibody targets are

79 extracellular and secreted proteins (collectively, the "exoproteome"). Because antibodies

80 are themselves large $(150 \mathrm{kDa})$ secreted proteins, they are most likely to recognize and

81 act upon targets that reside within the same extracellular compartment ${ }^{14}$. While state-of-

82 the-art technologies such as protein/peptide microarrays, proteome-scanning libraries

83 using phage (PhIP-seq) and bacterial display have enabled the discovery of novel

84 autoantibodies in a variety of disease ${ }^{15-23}$, these systems have limited sensitivity to

85 detect autoantibodies against extracellular targets. This is due in part to the inherent

86 difficulty of working with extracellular proteins, which often have unique folding

87 requirements that include signal peptide removal, disulfide bond formation, and post-

88 translational modifications such as glycosylation. Many of these features are not captured

89 by platforms that express proteins or peptides in prokaryotic systems. Similarly,

90 technologies that rely on the use of peptide fragments are not able to detect

91 autoantibodies that recognize "conformational" protein epitopes (i.e., three dimensional

92 epitopes present when a protein is folded into its native state). This limitation may

93 significantly hamper autoantibody detection, since as many as $90 \%$ of antibodies

94 recognize conformational epitopes as opposed to linear peptides ${ }^{24}$. 
96 Here, we describe Rapid Exoproteome Antigen Profiling (REAP), a new method to

97 discover functional antibodies against the exoproteome. REAP leverages yeast-display

98 technology to assess the presence of autoantibody responses to 2,688 extracellular 99 proteins present in patient serum or plasma samples through a next-generation 100 sequencing-based approach. We use REAP to screen a cohort of 77 APECED patients 101 and successfully identify known autoantibodies along with novel "public" (present in many 102 patients) and "private" (present in only a few patients) reactivities. We further apply REAP 103 to a cohort of 106 patients with SLE and identify autoantibodies targeting cytokines, 104 cytokine receptors, growth factors, extracellular matrix components, and 105 immunomodulatory cell surface proteins, and validate several of these reactivities through 106 orthogonal assays. In both SLE and APECED, we identify autoantibody responses that 107 are associated with disease severity and specific clinical disease manifestations. Finally, 108 we find that autoantibodies in SLE patients that target the co-inhibitory ligand PD-L2 and 109 the cytokine IL-33 have functional antagonist activity ex vivo. These results indicate that 110 REAP is broadly useful for the discovery of autoantibodies targeting the exoproteome and 111 that functional autoantibodies within patient populations may provide key insights into 112 disease pathogenesis and therapeutic approaches.

\section{Results}

\section{Development of Rapid Exoproteome Antigen Profiling}

116 To develop a system capable of detecting autoantibody responses against conformational 117 extracellular proteins, we elected to use yeast surface display to comprehensively sample 118 the human exoproteome (Fig. 1a). As eukaryotic cells, yeast contain several features that 119 enable them to express extracellular proteins, including endoplasmic reticulum 120 chaperones, glycosylation machinery, and disulfide bond proofreading systems ${ }^{25}$. 121 Accordingly, a diverse range of mammalian extracellular protein families have been 122 successfully expressed with yeast display, including proteins with folds such as the 123 immunoglobulin superfamily (IgSF), TNF superfamily (TNFSF), TNF receptor superfamily 124 (TNFRSF), von Willebrand factor A (vWFA) domains, fibronectin domain, leucine-rich 125 repeat (LRR), EGF-like, insulin-like, cytokines, growth factors, and even complicated 
126 assemblies like peptide:MHC complexes, T cell receptors, and intact antibodies ${ }^{26-41}$. We

127 therefore constructed a genetically-barcoded yeast-displayed exoproteome library of

128 approximately 2,700 human extracellular and secreted proteins. The library comprises

129 actively displayed proteins from a wide range of protein families and encompasses $87 \%$

130 of all human exoproteins with extracellular regions from 50-600 amino acids in length

131 (Fig. 1b, Supplementary Fig. 1a-c). While there is within-library heterogeneity in

132 individual protein abundance and the number of unique barcodes associated with each

133 gene, the library is relatively uniform and the vast majority of proteins fall within a narrow

134 range suited to coverage by standard next-generation sequencing approaches (Fig.

135 1c,d). Full details on the design and composition of the library are described in the

136 Methods and in Supplemental Table 1.

138 We next optimized procedures for high-throughput identification of seroreactivities 139 against proteins in our exoproteome library for REAP (Fig. 1d). Briefly, IgG purified from 140 patient serum or plasma is incubated with the yeast library. Autoantibody-coated cells are 141 then isolated by magnetic separation and deep sequencing of the library-encoded DNA 142 barcodes is used to identify the corresponding antigens encoded by these cells. To 143 quantify the degree of antibody reactivity to a given antigen, we developed a custom 144 scoring algorithm ("REAP Score") based on the enrichment of each antigen's barcodes 145 after selection (see Methods). Screening of the exoproteome library with a set of nine 146 conformation-specific monoclonal antibodies against a variety of extracellular proteins 147 showed that all antibody targets were detected specifically and robustly (Fig. 2a,b). To 148 further assess the conformational nature of proteins displayed in the library, we performed 149 a REAP screen using a panel of 30 recombinant proteins with known binding partners in 150 the library. REAP accurately detected the cognate binding partners for each of these 151 proteins, with minimal enrichment of off-target proteins (Fig. 2c).

\section{Evaluation of REAP performance in APECED}

154 To evaluate the capacity of REAP to detect exoproteome-directed autoantibodies in 155 complex patient samples such as polyclonal responses in serum, we screened a cohort 156 of 77 APECED patients (Supplementary Table 2). APECED, also known as autoimmune 
157 polyglandular syndrome type-1 (APS-1), is a rare genetic autoimmune disease caused 158 by mutations in the autoimmune regulator (AIRE) gene, resulting in loss of central 159 tolerance and the development of chronic mucocutaneous candidiasis (CMC), severe 160 endocrinopathies and other nonendocrine autoimmune sequelae such as pneumonitis, 161 hepatitis, alopecia, vitiligo, and vitamin B12 deficiency/pernicious anemia ${ }^{42}$. Interestingly, 162 APECED patients harbor widespread and pathognomonic autoantibodies targeting 163 numerous cytokines including type I and type III interferons, IL-22, IL-17A, and IL-17F43$164 \quad 47$. REAP readily identified autoantibody responses against these cytokines in APECED 165 patient samples, but not in samples from healthy controls (Fig. 3a). Furthermore, the 166 frequencies of these autoreactivities in APECED patients closely matched the 167 frequencies determined from previous reports using gold-standard methodologies such 168 as enzyme-linked immunosorbent assay (ELISA) and luciferase immunoprecipitation 169 system immunoassay (LIPS) (Fig. 3b) ${ }^{18,43,47}$. We also identified autoantibodies against 170 gastric intrinsic factor (GIF), lipocalin-1 (LCN1), IL-5, IL-6, protein disulfide-isomerase-like 171 protein of the testis (PDILT), and BPI fold containing family member 1 and 2 (BPIFA1/2), 172 which have been previously described in APECED ${ }^{18-21,48}$. With respect to GIF reactivities, 173 the results seen with REAP demonstrated strong concordance with anti-GIF ELISA 174 results from the same patients (Fig. 3c).

176 To investigate the reproducibility of REAP, we compared $\log _{2}[$ fold enrichment] between 177 technical (intra-assay) replicates across all APECED patient samples and found strong 178 positive correlations between replicates (median $R^{2}=0.914$; Supplementary Fig. 1d). 179 To investigate the sensitivity of REAP, we titrated varying amounts of IgG and performed 180 REAP and ELISA side-by-side for four autoantigens (Supplementary Fig. 1e,f). In each 181 case, REAP exhibited higher sensitivity than ELISA by 1-2 orders of magnitude, as seen 182 by the calculated $\mathrm{EC}_{50}$ values (Fig. 3d). Taken in aggregate, these data indicate that 183 REAP is capable of detecting known autoantibody responses against extracellular 184 proteins with high sensitivity and precision. 
188 Previous reports using protein microarrays and PhIP-seq have shown that APECED patients have greatly elevated numbers of autoantibody reactivities at a proteome-scale compared to healthy controls. Analyzing the REAP data, we found that global autoreactivity present in APECED also extends to the exoproteome (Fig. 3e,

192 Supplementary Fig. 2a). While some of the reactivities we observed have been 193 previously characterized, the screen also uncovered numerous previously undescribed 194 "public" (present in more than one patient) and "private" (present in only one patient) 195 reactivities. Two notable public reactivities were those against glycoprotein hormone 196 beta-5 (GPHB5), a thyrostimulin subunit, and pancreatic triacylglycerol lipase (PNLIP), a 197 tissue-restricted antigen that is regulated by AIRE in the thymus ${ }^{49}$. Using ELISA, we 198 confirmed the presence of autoantibody responses against these proteins and found that 199 the titers of autoantibodies were high, ranging from EC50s of approximately 1:100 to $2001: 10,000$ (Fig. 3f,g). We additionally were able to correlate particular serological 201 responses to specific, variable clinical features of APECED. For example, we found that 202 autoantibodies against lipocalin-1 (LCN1) and BPIFA1, which had previously been 203 identified in APECED patients with Sjogren's-like syndrome ${ }^{48}$, were enriched in a subset 204 of APECED patients with pneumonitis (6 out of 28 with pneumonitis), a life-threatening 205 non-endocrine complication of APECED, but universally negative in 49 patients without

206 pneumonitis or healthy controls (Fig. 3h). Of note, BPIFA1 reactivity was detected in a 207 patient with biopsy-proven pneumonitis without reactivity to the known lung-targeted 208 autoantibodies KCNRG and BPIFB1, which have an overall sensitivity of $\sim 75 \%$ but are negative in a quarter of patients with biopsy-proven pneumonitis ${ }^{50}$. Interestingly, the 210 single patient in our cohort with exocrine pancreatic insufficiency, a rare manifestation of 211 APECED ${ }^{42}$, uniquely harbored reactivity to colipase (CLPS), an essential cofactor for 212 pancreatic lipase and related lipases (Fig. 3a $)^{51}$. Thus, REAP enabled the detection of 213 novel autoantibody reactivities in the monogenic disease APECED, as well as 214 correlations of autoantibodies with clinical features of the disease.

216 REAP identifies previously undescribed autoantibody reactivities in SLE patients

217 We sought to apply REAP to study SLE, a systemic polygenic autoimmune disease 218 characterized by loss of tolerance to nucleic acids ${ }^{52}$. Though autoantibodies are a defining 
219 feature in SLE, particularly those against nucleic acids and nuclear protein complexes ${ }^{53}$, 220 the role of functional autoantibodies that target the exoproteome is less well established.

221 We thus performed REAP analysis on samples from a cohort of 106 SLE patients and 20 222 healthy controls. Patient and control demographics are shown in Supplementary Table 223 3. Compared to APECED, we found that exoproteome-targeting autoantibodies in SLE 224 patients were strikingly heterogeneous; though a wide variety of autoantigens were 225 identified, there were essentially no public autoantigens and most reactivities were 226 present in only a few patients (Fig. 4a). Several reactivities identified by REAP included 227 autoantigens that have previously been described in SLE such as IL-6, type I interferons, $228 \mathrm{IL}-1 \alpha$, and TNFa (including identification of a therapeutic anti-TNF antibody administered 229 to one of the patients). We further identified numerous novel autoantibodies targeting 230 other cytokines (e.g., IL-4, IL-33), chemokines (e.g., CXCL3, CCL8), growth factors (e.g., 231 VEGF-B, FGF-21), extracellular matrix components (e.g., epiphycan, vitrin), and 232 immunoregulatory cell surface proteins (e.g., FAS, PD-L2, B7-H4).

234 To validate the large number of candidate autoantibody reactivities identified by REAP, 235 we tested autoantibody reactivities against several different proteins using LIPS and 236 ELISA and subsequently confirmed 16 of these autoantigens (Table 1, Fig. 4f,i, 237 Supplementary Fig. 3a-h, j, n-r). The subset of confirmed autoantibody reactivities 238 consisted of both shared and private reactivities and included examples of potentially 239 pathological and well as immunomodulatory reactivities, such as those against the extracellular matrix component epiphycan (Supplementary Fig. 3n), the cytokine 241 receptor IL-18Rß (Supplementary Fig. 3p), the death receptor FAS/TNFRSF6 242 (Supplementary Fig. 3e), the co-inhibitory ligand PD-L2 (Fig. 4f), and the IL-1 family 243 cytokine IL-33 (Fig. 4i). We additionally characterized the titers and IgG isotypes for 244 several of these responses, finding that they spanned a wide range of titers (1:10 245 to $>1: 10,000$ ) and isotype classes (Supplementary Fig. 3n-r, t-v). Using these results, 246 as well as orthogonal validations of known APECED reactivities (Supplementary Fig. 3i$247 \mathrm{~m}$ ), we performed receiver operating characteristic (ROC) analysis to quantify the 248 performance of the REAP scoring algorithm. We found that REAP score sensitively and 249 specifically predicted autoantibody reactivity by ELISA and/or LIPS, with an area under 
250 the curve (AUC) of 0.892 (Supplementary Fig. 3s). Because REAP exhibits greater 251 sensitivity for some antigens than the ELISA/LIPS "gold standards" (as was the case for 252 type I IFN autoantibodies in APECED), this number may represent a conservative 253 estimate of the true performance of REAP in predicting autoantibody reactivity.

Exoproteome-targeting autoantibodies in SLE are functional and correlate with disease severity

257 Given the broad distribution of autoantibody responses in SLE, we wondered if particular 258 responses or patterns of reactivity were associated with specific clinical features of the 259 disease. At a global level, we found that the total numbers of autoantibody reactivities 260 identified with REAP correlated with worse clinical severity, as measured by the Systemic 261 Lupus Erythematosus Disease Activity Index (SLEDAI) score ${ }^{54}$. In particular, we found 262 that samples from patients with severe disease (SLEDAI score $\geq 9$ ) had significantly 263 increased numbers of autoantibodies compared to healthy controls (Fig. 4b, 264 Supplementary Fig. 2b). Furthermore, SLE patients in all severity groups had reactivities 265 that were not observed in healthy individuals and these patterns of reactivity were 266 associated with particular SLE disease phenotypes. For instance, we found that autoantibody reactivities against the chemokine CCL8, the cytokine IFN-alpha-6, and the 268 C-type lectin CD248 (endosialin) were significantly associated with hematuria and that 269 VEGF-B reactivities were associated with leukopenia (Fig. 4c). Additionally, patients positive for CCL8 reactivity had significantly higher SLEDAI scores, indicating more 272 of immunoregulatory proteins (PD-L2, RAET1E, CD44, B7H4, BTNL8, CD300E, IER3, 273 TNFRSF6, CD300LG, LILRB2, IGLL1, and LILRB4) had significantly lower SLEDAI 274 scores compared to patients negative for these autoantibodies (Fig. 4e).

276 Finally, we characterized the functionality of autoantibodies against two novel 277 autoantigens identified by REAP, PD-L2 and IL-33. As the primary biological function of 278 PD-L2 is mediated by its binding to its receptor PD-1, we tested whether autoantibodies 279 against PD-L2 could block this interaction. Serum samples from an SLE patient with anti280 PD-L2 autoantibodies were present at titers >1:100 and inhibited the interaction between 
281 PD-L2 and PD-1 in a dose-dependent manner, while serum from a control patient without

282 anti-PD-L2 autoantibodies did not (Fig. 4f-h). To test the functional effects of anti-IL-33

283 autoantibodies, we used a HEK-Blue IL-33 reporter cell line, which produces secreted

284 alkaline phosphatase downstream of an NFKB promoter that is activated by the IL-33

285 pathway. Bulk IgG (isolated via protein $\mathrm{G}$ ) from the SLE patient harboring anti-IL-33

286 autoantibodies potently neutralized IL-33 signaling with an IC50 less than $0.01 \mathrm{mg} / \mathrm{mL}$,

287 while IgG from a control patient without anti-IL-33 autoantibodies had no neutralizing

288 effect (Fig. 4i-k). These findings underscore the ability of REAP to discover novel

289 autoantibodies with functional biological effects.

\section{Discussion}

292 In the present study we show that REAP is a sensitive and high-throughput platform for

293 discovery of exoproteome-directed autoantibodies. By querying antigens in a 294 conformationally-active state, REAP enables identification of autoantibodies that are 295 difficult to detect, if not entirely invisible to other technologies. This was particularly 296 evident in our screen of APECED samples, as we found that REAP was considerably 297 more accurate in detecting a well-defined subset of known extracellular autoantigen 298 reactivities compared to protein arrays and phage-peptide display approaches.

299 Furthermore, REAP enabled the identification of numerous previously undescribed 300 autoantigens in APECED patients, a surprising finding given how extensively 301 autoantibodies have been studied in this patient population.

303 We also identified a large set of previously undescribed autoantibody reactivities against 304 the exoproteome in SLE patients, a considerably more heterogeneous population than 305 APECED. The vast majority of these novel autoreactivities were relatively private with a 306 prevalence of $<5 \%$ and in some cases present in only a single patient. Though these 307 autoantibody responses are rare, our studies suggest that they can exert large biological 308 effects that could meaningfully impact disease progression, akin to the effect of rare 309 genetic variants. For example, we identified a single SLE patient with mild disease activity 310 (SLEDAI score of 1) who had extraordinarily high-titer autoantibodies against IL-33 that 311 potently neutralized IL-33 signaling in vitro. This suggests that these IL-33 antibodies may 
312 have played a protective role that ameliorated the severity of the disease in this individual 313 and, by extension, that IL-33 blockade could represent a potential therapeutic strategy in 314 SLE. Indeed, circulating IL-33 concentrations are elevated in SLE patients and are 315 positively correlated with C-reactive protein concentrations and clinical manifestations 316 such as thrombocytopenia and erythrocytopenia ${ }^{55,56}$. Similarly, preclinical studies in 317 mouse models have demonstrated that IL-33 exposure is associated with autoantibody 318 production and that neutralization of IL-33 suppresses lupus-like disease ${ }^{57,58}$. Beyond IL31933 , we also found that SLE patients with autoreactivity against a set of immunoreceptors 320 had substantially lower disease severity, indicating that disruption of those pathways 321 and/or opsonization of cells that express the receptors could similarly exert a protective 322 effect. Future investigation is warranted to determine the prevalence of these 323 autoantibodies in SLE patients and their potential protective effects on a larger, 324 confirmatory cohort. Nevertheless, our finding that functional autoantibodies responses 325 are highly variable between patients underscores the need for technologies like REAP that can provide comprehensive, unbiased antibody profiling for large numbers of

327 patients. Without sufficient sample throughput and representation of the exoproteome, 328 these rare, but impactful autoantibody responses might not be readily detected.

330 REAP does have important limitations. While our data indicate that most exoproteome 331 antigens are displayed on the surface of yeast and we additionally demonstrated that 332 dozens of the library members are biochemically active (via recapitulating known binding 333 interactions), not all members of the exoproteome can be expressed in the yeast system. 334 This may be due to lack of specific chaperones, expression partners, or post-translational 335 modifications required for protein folding and activity. Furthermore, while yeast do perform 336 O- and $\mathrm{N}$ - linked glycosylation, their glycosylation patterns are characterized by a 337 hypermannose structure that is highly divergent from glycosylation seen in humans ${ }^{59}$. 338 Thus, autoantibodies recognizing specific glycoforms of their antigens would not be 339 detected with REAP. Further improvement in the REAP platform could therefore involve 340 yeast strain engineering to co-express mammalian chaperone proteins to enhance folding 341 of human antigens and glycosylation enzymes to produce more human-like glycosylation 342 patterns, as has been described for the yeast species Pichia pastoris ${ }^{60}$. 
344 Though we initially applied REAP to the study of autoimmune conditions, an intriguing 345 avenue of future study with REAP and other serological profiling technologies is to 346 characterize autoantibody responses in diseases such as cancer, infectious diseases,

347 and neurological conditions that are not considered to have a primarily autoimmune 348 etiology. Identification of disease-modifying antibody responses in such conditions could 349 implicate new molecular pathways that contribute to disease pathology as well as novel 350 therapeutic targets and molecular diagnostics. Furthermore, patient autoantibodies could 351 represent potential therapeutic agents themselves. Technologies such as REAP can 352 enable these discoveries by revealing the diverse landscape of functional autoantibody 353 responses that influence health and disease.

Materials and Methods

356 Library production.

357 Library design. An initial library of 3093 human extracellular proteins was assembled 358 based on protein domains, immunological functions, and yeast-display compatibility. The 359 extracellular portion of each protein was identified by manual inspection of topological 360 domains annotated in the SwissProt database (January 2018). For proteins with uncertain 361 topology, full sequences were run through SignalP 4, Topcons, and GPIPred to identify 362 most likely topologies. For proteins with multiple extracellular portions, in general the 363 longest individual region was chosen for initial amplification. cDNAs for chosen proteins 364 were purchased from GE Dharmacon or DNASU. The protein sequences were further 365 modified to match isoforms available in purchased cDNAs. An inventory of antigens 366 included in the library are compiled in supplementary table 1.

368 Library construction. A two-step PCR process was used to amplify cDNAs for cloning into 369 a barcoded yeast-display vector. cDNAs were amplified with gene-specific primers, with 370 the forward primer containing a 5 ' sequence (CTGTTATTGCTAGCGTTTTAGCA) and the 371 reverse primer containing a 5' sequence (GCCACCAGAAGCGGCCGC) for template 372 addition in the second step of PCR. PCR reactions were conducted using $1 \mu \mathrm{L}$ pooled 373 cDNA, gene-specific primers, and the following PCR settings: $98^{\circ} \mathrm{C}$ denaturation, $58{ }^{\circ} \mathrm{C}$ 
374 annealing, $72^{\circ} \mathrm{C}$ extension, 35 rounds of amplification. $1 \mu \mathrm{L}$ of PCR product was used for 375 direct amplification by common primers Aga2FOR and 159REV, and the following PCR 376 settings: $98^{\circ} \mathrm{C}$ denaturation, $58^{\circ} \mathrm{C}$ annealing, $72^{\circ} \mathrm{C}$ extension, 35 rounds of amplification. 377 PCR product was purified using magnetic PCR purification beads (AvanBio). $90 \mu \mathrm{L}$ beads 378 were added to the PCR product and supernatant was removed. Beads were washed twice 379 with $200 \mu \mathrm{L} 70 \%$ ethanol and resuspended in $50 \mu \mathrm{L}$ water to elute PCR products from the 380 beads. Beads were removed from purified PCR products. The 15bp barcode fragment 381 was constructed by overlap PCR. 4 primers (bc1, bc2, bc3, bc4; sequences listed below) 382 were mixed in equimolar ratios and used as a template for a PCR reaction using the 383 following PCR settings: $98^{\circ} \mathrm{C}$ denaturation, $55^{\circ} \mathrm{C}$ annealing, $72^{\circ} \mathrm{C}$ extension, 35 rounds 384 of amplification. Purified product was reamplified with the first and fourth primer using 385 identical PCR conditions. PCR products were run on $2 \%$ agarose gels and purified by gel extraction (Qiagen). Purified barcode and gene products were combined with linearized yeast-display vector (pDD003 digested with EcoRI and BamHI) and electroporated into JAR300 yeast using a 96-well electroporator (BTX Harvard Apparatus) using the following electroporation conditions: Square wave, $500 \mathrm{~V}, 5 \mathrm{~ms}$ pulse, $2 \mathrm{~mm}$ gap. Yeast were immediately recovered into $1 \mathrm{~mL}$ liquid synthetic dextrose medium lacking uracil (SDO Ura) in 96-well deep well blocks and grown overnight at $30^{\circ} \mathrm{C}$. Yeast were passaged once by 1:10 dilution in SDO-Ura, then frozen as glycerol stocks. To construct the final library, $2.5 \mu \mathrm{L}$ of all wells were pooled and counted. A limited dilution of 300,000 clones was subsampled and expanded in SDO-Ura. Expression was induced by passaging into synthetic galactose medium lacking uracil (SGO-Ura) at a $1: 10$ dilution and growing at $30^{\circ} \mathrm{C}$ overnight. $10^{8}$ yeast were pelleted and resuspended in $1 \mathrm{~mL}$ PBE (PBS with $0.5 \%$ BSA and $0.5 \mathrm{mM}$ EDTA) containing 1:100 anti-FLAG PE antibody (BioLegend). Yeast were stained at $4^{\circ}$ for 75 minutes, then washed twice with $1 \mathrm{~mL}$ PBE and sorted for FLAG display on a Sony SH800Z cell sorter. Sorted cells were expanded in SDO-Ura 400 supplemented with $35 \mu \mathrm{g} / \mathrm{mL}$ chloramphenicol, expanded, and frozen as the final library.

401 bc1-TTGTTAATATACCTCTATACTTTAACGTCAAGGAGAAAAAACCCCGGATC 402 bc2-

403 CTGCATCCTTTAGTGAGGGTTGAANNNNNNNNNNNNNNNTTCGATCCGGGGTTTTT 404 TCTCCTTG 
405 bc3-

406 TTCAACCCTCACTAAAGGATGCAGTTACTTCGCTGTTTTTCAATATTTTCTGTTATTG

407 C

408 bc4-TGCTAAAACGCTAGCAATAACAGAAAATATTGAAAAACAGCG

Barcode identification. Barcode-gene pairings were identified using a custom Tn5-based sequence approach. Tn5 transposase was purified as previously described, using the on-

412 column assembly method for loading oligos ${ }^{61}$. DNA was extracted from the yeast library 413 using Zymoprep-96 Yeast Plasmid Miniprep kits or Zymoprep Yeast Plasmid Miniprep II 414 kits (Zymo Research) according to standard manufacturer protocols. $5 \mu \mathrm{L}$ of purified 415 plasmid DNA was digested with $\mathrm{Tn} 5$ in a $20 \mu \mathrm{L}$ total reaction as previously described. 2 $416 \mu \mathrm{L}$ of digested DNA was amplified using primers index 1 and index2, using the following 417 PCR settings: $98^{\circ} \mathrm{C}$ denaturation, $56{ }^{\circ} \mathrm{C}$ annealing, $72{ }^{\circ} \mathrm{C}$ extension, 25 rounds of 418 amplification. The product was run on a $2 \%$ gel and purified by gel extraction (Qiagen). 419 Purified product was amplified using primers index3 and index4, using the following PCR 420 settings: $98^{\circ} \mathrm{C}$ denaturation, $60^{\circ} \mathrm{C}$ annealing, $72^{\circ} \mathrm{C}$ extension, 25 rounds of amplification. 421 In parallel, the barcode region alone was amplified using primers index 1 and index5, 422 using the following PCR settings: $98^{\circ} \mathrm{C}$ denaturation, $56^{\circ} \mathrm{C}$ annealing, $72^{\circ} \mathrm{C}$ extension, 42325 rounds of amplification. The product was run on a $2 \%$ gel and purified by gel extraction 424 (Qiagen). Purified product was amplified using primers index 3 and index6, using the 425 following PCR settings: $98^{\circ} \mathrm{C}$ denaturation, $60^{\circ} \mathrm{C}$ annealing, $72{ }^{\circ} \mathrm{C}$ extension, 20 rounds 426 of amplification. Both barcode and digested fragment products were run on a $2 \%$ gel and 427 purified by gel extraction (Qiagen). NGS library was sequenced using an Illumina MiSeq 428 and Illumina v3 MiSeq Reagent Kits with 150 base pair single-end sequencing according 429 to standard manufacturer protocols. Gene-barcode pairings were identified using custom 430 code. Briefly, from each read, the barcode sequence was extracted based on the 431 identification of the flanking constant vector backbone sequences, and the first $25 \mathrm{bp}$ of 432 sequence immediately following the constant vector backbone-derived signal peptide 433 were extracted and mapped to a gene identity based on the first $25 \mathrm{bp}$ of all amplified 434 cDNA constructs. The number of times each barcode was paired with an identified gene 435 was calculated. Barcode-gene pairings that were identified more than twice, with an 
436 overall observed barcode frequency of greater than $.0002 \%$ were compiled. For barcodes

437 with multiple gene pairings matching the above criteria, the best-fit gene was manually

438 identified by inspection of all barcode-gene pairing frequencies and, in general, 439 identification of the most abundant gene pairing. In the final library, 2,688 genes were 440 confidently mapped to 35,835 barcodes.

442 Rapid Extracellular Antigen Profiling.

443 Antibody purification and yeast adsorption. $20 \mu \mathrm{L}$ protein $\mathrm{G}$ magnetic resin (Lytic 444 Solutions) was washed twice with $100 \mu \mathrm{L}$ sterile PBS, resuspended in $50 \mu \mathrm{L}$ PBS, and 445 added to $50 \mu \mathrm{L}$ serum or plasma. Serum-resin mixture was incubated for three hours at $446 \quad 4{ }^{\circ} \mathrm{C}$ with shaking. Resin was washed five times with $200 \mu \mathrm{L}$ PBS, resuspended in $90 \mu \mathrm{L}$ $447100 \mathrm{mM}$ glycine $\mathrm{pH} 2.7$, and incubated for five minutes at room temperature. Supernatant 448 was extracted and added to $10 \mu \mathrm{L}$ sterile $1 \mathrm{M}$ Tris $\mathrm{pH} 8.0$ (purified IgG). Empty vector 449 (pDD003) yeast were expanded in SDO-Ura at $30^{\circ} \mathrm{C}$. One day later, yeast were induced 450 by 1:10 dilution in SGO-Ura for 24 hours. $10^{8}$ induced yeast were washed twice with 200 $451 \mu \mathrm{L}$ PBE (PBS with 0.5\% BSA and $0.5 \mathrm{mM}$ EDTA), resuspended with $100 \mu \mathrm{L}$ purified IgG, 452 and incubated for three hours at $4{ }^{\circ} \mathrm{C}$ with shaking. Yeast-IgG mixtures were placed into 45396 well 0.45 um filter plates (Thomas Scientific) and yeast-depleted IgG was eluted into 454 sterile 96 well plates by centrifugation at $3000 \mathrm{~g}$ for 3 minutes.

Antibody yeast library selections. Transformed yeast were expanded in SDO-Ura at 30 ${ }^{\circ} \mathrm{C}$. One day later, at an optical density (OD) below 8 , yeast were induced by resuspension at an OD of 1 in SGO-Ura supplemented with ten percent SDO-Ura and culturing at 30 $459{ }^{\circ} \mathrm{C}$ for 20 hours. Prior to selection, $400 \mu \mathrm{L}$ pre-selection library was set aside to allow for comparison to post-selection libraries. $10^{8}$ induced yeast were washed twice with $200 \mu \mathrm{L}$

461 PBE and added to wells of a sterile 96-well v-bottom microtiter plate. Yeast were 462 resuspended in $100 \mu \mathrm{L}$ PBE containing appropriate antibody concentration and incubated 463 with shaking for 1 hour at $4^{\circ} \mathrm{C}$. Unless otherwise indicated, $10 \mu \mathrm{g}$ antibody per well was 464 used for human serum or plasma derived antibodies and $1 \mu \mathrm{g}$ antibody was used for 465 monoclonal antibodies. Yeast were washed twice with $200 \mu \mathrm{L}$ PBE, resuspended in 100 $466 \mu \mathrm{L}$ PBE with a 1:100 dilution of biotin anti-human IgG Fc antibody (clone HP6017, 
467 BioLegend) for human serum or plasma derived antibodies or a 1:25 dilution of biotin goat 468 anti-rat or anti-mouse IgG antibody (A16088, Thermo Fisher Scientific; A18869, Thermo 469 Fisher Scientific) for monoclonal antibodies. Yeast-antibody mixtures were incubated with 470 shaking for 30 minutes at $4^{\circ} \mathrm{C}$. Yeast were washed twice with $200 \mu \mathrm{L}$ PBE, resuspended 471 in $100 \mu \mathrm{L}$ PBE with a 1:20 dilution of Streptavidin MicroBeads (Miltenyi Biotec), and 472 incubated with shaking for 30 minutes at $4{ }^{\circ} \mathrm{C}$. Yeast were then pelleted and kept on ice. 473 Multi-96 Columns (Miltenyi Biotec) were placed into a MultiMACS M96 Separator (Miltenyi 474 Biotec) and the separator was placed into positive selection mode. All following steps 475 were carried out at room temperature. Columns were equilibrated with $400 \mu \mathrm{L} 70 \%$ 476 ethanol followed by $700 \mu \mathrm{L}$ degassed PBE. Yeast were resuspended in $200 \mu \mathrm{L}$ degassed 477 PBE and placed into the columns. After the mixture had completely passed through, 478 columns were washed three times with $700 \mu \mathrm{L}$ degassed PBE. To elute the selected 479 yeast, columns were removed from the separator and placed over 96-well deep well 480 plates. $700 \mu \mathrm{L}$ degassed PBE was added to each well of the column and the column and 481 deep well plate were spun at $50 \mathrm{~g}$ for 30 seconds. This process was repeated 3 times. 482 Selected yeast were pelleted, and recovered in $1 \mathrm{~mL} \mathrm{SDO} \mathrm{-Ura} \mathrm{at} 30^{\circ} \mathrm{C}$.

484 Recombinant protein yeast library selections. All pre-selection and yeast induction steps 485 were performed identically as those of the antibody yeast library selections. $10^{8}$ induced 486 yeast were washed twice with $200 \mu \mathrm{L} \mathrm{PBE}$ and added to wells of a sterile 96-well v-bottom 487 microtiter plate. Yeast were resuspended in $100 \mu \mathrm{L}$ PBE containing $75 \mu \mathrm{L}$ clarified protein 488 expression supernatant and incubated with shaking for 1 hour at $4^{\circ} \mathrm{C}$. Yeast were washed 489 twice with $200 \mu \mathrm{L}$ PBE, resuspended in $100 \mu \mathrm{L}$ PBE with $5 \mu \mathrm{L} \mu \mathrm{MACS}$ Protein G 490 MicroBeads (Miltenyi Biotec), and incubated with shaking for 30 minutes at $4{ }^{\circ} \mathrm{C}$. Selection 491 of yeast using the MultiMACS M96 Separator and subsequent steps were performed 492 identically as those of the antibody yeast library selections.

494 Next generation sequencing library preparation and sequencing. DNA was extracted from 495 yeast libraries using Zymoprep-96 Yeast Plasmid Miniprep kits or Zymoprep Yeast 496 Plasmid Miniprep II kits (Zymo Research) according to standard manufacturer protocols. 497 A first round of PCR was used to amplify a DNA sequence containing the protein display 
498 barcode on the yeast plasmid. PCR reactions were conducted using $1 \mu \mathrm{L}$ plasmid DNA, 499 159_DIF2 and 159_DIR2 primers (sequences listed below), and the following PCR 500 settings: $98^{\circ} \mathrm{C}$ denaturation, $58^{\circ} \mathrm{C}$ annealing, $72^{\circ} \mathrm{C}$ extension, 25 rounds of amplification.

501 PCR product was purified using magnetic PCR purification beads (AvanBio). $45 \mu \mathrm{L}$ beads 502 were added to the PCR product and supernatant was removed. Beads were washed twice 503 with $100 \mu \mathrm{L} 70 \%$ ethanol and resuspended in $25 \mu \mathrm{L}$ water to elute PCR products from the 504 beads. Beads were removed from purified PCR products. A second round of PCR was 505 conducted using $1 \mu \mathrm{L}$ purified PCR product, Nextera i5 and i7 dual-index library primers 506 (Illumina), and the following PCR settings: $98{ }^{\circ} \mathrm{C}$ denaturation, $58{ }^{\circ} \mathrm{C}$ annealing, $72{ }^{\circ} \mathrm{C}$ 507 extension, 25 rounds of amplification. PCR products were pooled and run on a $1 \%$ 508 agarose gel. The band corresponding to 257 base pairs was cut out and DNA (NGS 509 library) was extracted using a QIAquick Gel Extraction Kit (Qiagen) according to standard 510 manufacturer protocols. NGS library was sequenced using an Illumina MiSeq and Illumina 511 v3 MiSeq Reagent Kits with 75 base pair single-end sequencing or using an Illumina 512 NovaSeq 6000 and Illumina NovaSeq S4 200 cycle kit with 101 base pair paired-end 513 sequencing according to standard manufacturer protocols. A minimum of 50,000 reads 514 per sample was collected and the pre-selection library was sampled at ten times greater 515 depth than other samples.

516 159_DIF2-

517 TCGTCGGCAGCGTCAGATGTGTATAAGAGACAGNNNNNNNNNNGAGAAAAAACCC 518 CGGATCG

519 159_DIR2-

520 GTCTCGTGGGCTCGGAGATGTGTATAAGAGACAGNNNNNNNNNNACGCTAGCAAT 521 AACAGAAAATATTG

523 Data analysis. REAP scores were calculated as follows. First, barcode counts were 524 extracted from raw NGS data using custom codes and counts from technical replicates 525 were summed. Next, aggregate and clonal enrichment was calculated using edgeR ${ }^{62}$ and 526 custom codes. For aggregate enrichment, barcode counts across all unique barcodes 527 associated with a given protein were summed, library sizes across samples were 528 normalized using default edgeR parameters, common and tagwise dispersion were 
529 estimated using default edgeR parameters, and exact tests comparing each sample to 530 the pre-selection library were performed using default edgeR parameters. Aggregate 531 enrichment is thus the log2 fold change values from these exact tests with zeroes in the 532 place of negative fold changes. Log2 fold change values for clonal enrichment were 533 calculated in an identical manner, but barcode counts across all unique barcodes 534 associated with a given protein were not summed. Clonal enrichment for a given reactivity 535 was defined as the fraction of clones out of total clones that were enriched (log2 fold 536 change $\geq 2)$. Aggregate $\left(E_{a}\right)$ and clonal enrichment $\left(E_{c}\right)$ for a given protein, a scaling 537 factor $\left(\beta_{u}\right)$ based on the number of unique yeast clones (yeast that have a unique DNA 538 barcode) displaying a given protein, and a scaling factor $\left(\beta_{f}\right)$ based on the overall 539 frequency of yeast in the library displaying a given protein were used as inputs to calculate 540 the REAP score, which is defined as follows.

$$
\operatorname{REAP} \text { score }=E_{a} *\left(E_{c}\right)^{2} * \beta_{u} * \beta_{f}
$$

$542 \beta_{u}$ and $\beta_{f}$ are logarithmic scaling factors that progressively penalize the REAP score of 543 proteins with low numbers of unique barcodes or low frequencies in the library. $\beta_{u}$ is

544 applied to proteins with $\leq 5$ unique yeast clones in the library and $\beta_{f}$ is applied to proteins 545 with a frequency $\leq 0.0001$ in the library. $\beta_{f}$ was implemented to mitigate spurious 546 enrichment signals from low frequency proteins, which could occur due to sequencing 547 errors or stochasticity in the selection process. $\beta_{u}$ was implemented because the clonal 548 enrichment metric is less valid for proteins with low numbers of unique yeast clones, 549 decreasing confidence in the validity of the reactivity. $\beta_{u}$ and $\beta_{f}$ are defined as follows 550 where $x_{u}$ is the number of unique yeast clones for a given protein and $x_{f}$ is the log10 551 transformed frequency of a given protein in the library.

$$
\begin{aligned}
& \beta_{u}=\frac{\ln \left(x_{u}+0.5\right)}{1.705} \\
& \beta_{f}=\frac{\ln \left(x_{f}+7.1\right)}{1.16}
\end{aligned}
$$

\section{Recombinant protein production.}

556 REAP recombinant protein production. Proteins were produced as human IgG1 FC 557 fusions to enable binding of secondary antibody and magnetic beads to the produced 
558 proteins during the REAP process. Sequences encoding the extracellular portions of 559 proteins-of-interests that were present in the yeast display library were cloned by Gibson 560 assembly into a modified pD2610-v12 plasmid (ATUM). Modifications include addition of 561 an H7 signal sequence followed by a (GGGGS)3 linker and a truncated human IgG1 Fc 562 (N297A). Protein-of-interest sequences were inserted directly downstream of the H7 563 leader sequence. Protein was produced by transfection into Expi293 cells (Thermo Fisher 564 Scientific) in 96-well plate format. One day prior to transfection, cells were seeded at a 565 density of 2 million cells per $\mathrm{mL}$ in Expi293 Expression Medium (Thermo Fisher 566 Scientific). In a 96-well plate, $0.5 \mu \mathrm{g}$ plasmid DNA was diluted added to $25 \mu \mathrm{L}$ Opti-MEM 567 (Thermo Fisher Scientific) and mixed gently. In a separate 96-well plate, $1.35 \mu \mathrm{L}$ 568 ExpiFectamine was added to $25 \mu \mathrm{L}$ Opti-MEM and mixed gently. The ExpiFectamine569 Opti-MEM mixture was added to the diluted DNA, mixed gently, and incubated for 20 570 minutes at room temperature. Expi293 cells were diluted to a density of 2.8 million cells 571 per $\mathrm{mL}$ and $500 \mu \mathrm{L}$ of cells were added to each well of a 96-well deep well plate. $50 \mu \mathrm{L}$ 572 of the DNA-ExpiFectamine-Opti-MEM mixture was added to each well. The plate was 573 sealed with Breathe-Easier sealing film (Diversified Biotech) and incubated in a humidified 574 tissue culture incubator $\left(37^{\circ} \mathrm{C}, 8 \% \mathrm{CO}_{2}\right)$ with shaking at 1,200 rpm so that cells were kept 575 in suspension. 18-20 hours post-transfection, $25 \mu \mathrm{L}$ enhancer 2 and $2.5 \mu \mathrm{L}$ enhancer 1 576 (Thermo Fisher Scientific) were added to each well. 4 days post-transfection, media was 577 clarified by centrifugation at $3000-4000 \mathrm{~g}$ for 5 minutes. Clarified media was used for 578 recombinant protein REAP.

580 ELISA protein production. Sequences encoding the extracellular portions of proteins-of581 interests that were present in the yeast display library were cloned by Gibson assembly 582 into pEZT_Dlux, a modified pEZT-BM vector. The pEZT-BM vector was a gift from Ryan 583 Hibbs (Addgene plasmid \#74099). Modifications included insertion of an H7 Leader 584 Sequence followed by an AviTag (Avidity), HRV 3C site, protein C epitope, and an 8x his 585 tag. Protein-of-interest sequences were inserted directly downstream of the $\mathrm{H} 7$ leader 586 sequence. Protein was produced by transfection into Expi293 cells (Thermo Fisher 587 Scientific) according to standard manufacturer protocols. Transfected cells were 588 maintained according to manufacturer protocols. 4 days post-transfection, media was 
589 clarified by centrifugation at $300 \mathrm{~g}$ for 5 minutes. Protein was purified from clarified media 590 by nickel-nitrilotriacetic acid (Ni-NTA) chromatography and desalted into HEPES buffered 591 saline +100 mM sodium chloride, $\mathrm{pH}$ 7.5. Protein purity was verified by SDS-PAGE.

592

593 Biotinylated protein production. Sequences encoding the extracellular portions of 594 proteins-of-interests were cloned into pEZT_Dlux as described above. Protein was 595 expressed and purified as described above minus desalting. Enzymatic biotinylation with 596 BirA ligase was performed and protein was purified by size-exclusion fast protein liquid 597 chromatography using a NGC Quest 10 Chromatography System (Bio-Rad).

598

599 LIPS protein production. Sequences encoding Lucia luciferase (InvivoGen) fused by a 600 GGSG linker to the N-terminus of the protein-of-interest extracellular portion (as defined 601 above) were cloned by Gibson assembly into pEZT-BM. Protein was produced by 602 transfection into Expi293 cells (Thermo Fisher Scientific) according to standard 603 manufacturer protocols. Transfected cells were maintained according to manufacturer 604 protocols. 3 days post-transfection, media was clarified by centrifugation at $300 \mathrm{~g}$ for 5 605 minutes. Clarified media was used in luciferase immunoprecipitation systems assays.

607 Enzyme-linked immunosorbent assays (ELISAs).

608200 or $400 \mathrm{ng}$ of purchased or independently produced recombinant protein in $100 \mu \mathrm{L}$ of 609 PBS pH 7.0 was added to 96-well flat bottom Immulon 2HB plates (Thermo Fisher 610 Scientific) and placed at $4{ }^{\circ} \mathrm{C}$ overnight. Plates were washed once with $225 \mu \mathrm{L}$ ELISA 611 wash buffer (PBS + 0.05\% Tween 20) and $150 \mu \mathrm{L}$ ELISA blocking buffer (PBS + 2\% 612 Human Serum Albumin) was added to the well. Plates were incubated with shaking for 2 613 hours at room temperature. ELISA blocking buffer was removed from the wells and 614 appropriate dilutions of sample serum in $100 \mu \mathrm{L}$ ELISA blocking buffer were added to 615 each well. Plates were incubated with shaking for 2 hours at room temperature. Plates 616 were washed 6 times with $225 \mu \mathrm{L}$ ELISA wash buffer and 1:5000 goat anti-human IgG 617 HRP (Millipore Sigma) or anti-human IgG isotype specific HRP (Southern Biotech; IgG1: 618 clone HP6001, IgG2: clone 31-7-4, IgG3: clone HP6050, IgG4: clone HP6025) in $100 \mu L$ 619 ELISA blocking buffer was added to the wells. Plates were incubated with shaking for 1 
620 hour at room temperature. Plates were washed 6 times with $225 \mu \mathrm{L}$ ELISA wash buffer.

$62150 \mu \mathrm{L}$ TMB substrate (BD Biosciences) was added to the wells and plates were incubated

622 for 15 minutes (pan-IgG ELISAs) or 20 minutes (isotype specific IgG ELISAs) in the dark

623 at room temperature. $50 \mu \mathrm{L} 1 \mathrm{M}$ sulfuric acid was added to the wells and absorbance at

$624450 \mathrm{~nm}$ was measured in a Synergy HTX Multi-Mode Microplate Reader (BioTek).

625

626 Luciferase immunoprecipitation systems (LIPS) assays.

627 Pierce Protein A/G Ultralink Resin (5 $\mu \mathrm{L}$; Thermo Fisher Scientific) and $1 \mu \mathrm{L}$ sample 628 serum in $100 \mu \mathrm{L}$ Buffer A (50 mM Tris, $150 \mathrm{mM} \mathrm{NaCl}, 0.1 \%$ Triton X-100, pH 7.5) was 629 added to 96-well opaque Multiscreen HTS 96 HV 0.45 um filter plates (Millipore Sigma). 630 Plates were incubated with shaking at $300 \mathrm{rpm}$ for 1 hour at room temperature. 631 Supernatant in wells was removed by centrifugation at $2000 \mathrm{~g}$ for 1 minute. Luciferase 632 fusion protein ( $\left.10^{6} \mathrm{RLU}\right)$ was added to the wells in $100 \mu \mathrm{L}$ Buffer A. Plates were incubated 633 with shaking at $300 \mathrm{rpm}$ for 1 hour at room temperature. Using a vacuum manifold, wells 634 were washed 8 times with $100 \mu \mathrm{L}$ Buffer A followed by 2 washes with $100 \mu \mathrm{L}$ PBS. 635 Remaining supernatant in wells was removed by centrifugation at $2000 \mathrm{~g}$ for 1 minute. 636 Plates were dark adapted for 5 minutes. An autoinjector equipped Synergy HTX Multi637 Mode Microplate Reader (BioTek) was primed with QUANTI-Luc Gold (InvivoGen). Plates 638 were read using the following per well steps: $50 \mu \mathrm{L}$ QUANTI-Luc Gold injection, 4 second 639 delay with shaking, read luminescence with an integration time of 0.1 seconds and a read 640 height of $1 \mathrm{~mm}$.

641

642 PD-L2 blocking assay.

643 A single clone of PD-L2 displaying yeast was isolated from the library and expanded in

644 SDO-Ura at $30^{\circ} \mathrm{C}$. Yeast were induced by 1:10 dilution into SGO-Ura and culturing at 30 $645{ }^{\circ} \mathrm{C}$ for 24 hours. $10^{5}$ induced PD-L1 yeast were washed twice with $200 \mu \mathrm{L}$ PBE and added 646 to wells of a 96-well v-bottom microtiter plate. Yeast were resuspended in $25 \mu \mathrm{L}$ PBE 647 containing serial dilutions of sample serum and incubated with shaking for 1 hour at $4{ }^{\circ} \mathrm{C}$. 648 PD-1 tetramers were prepared by incubating a 5:1 ratio of biotinylated PD-1 and PE 649 streptavidin (BioLegend) for 10 minutes on ice in the dark. Yeast were washed twice with $650200 \mu \mathrm{L}$ PBE, resuspended in $25 \mu \mathrm{L}$ PBE containing $10 \mathrm{nM}$ previously prepared PD-1 
651 tetramers, and incubated with shaking for 1 hour at $4^{\circ} \mathrm{C}$. Yeast were washed twice with $652200 \mu \mathrm{L}$ PBE and resuspended in $75 \mu \mathrm{L}$ PBE. PE fluorescent intensity was quantified by 653 flow cytometry using a Sony SA3800 Spectral Cell Analyzer. Percent max binding was 654 calculated based on fluorescent PD-1 tetramer binding in the absence of any serum.

\section{IL-33 neutralization assay.}

657 IL-33 reporter cell line construction. The full-length coding sequence for ST2 was cloned 658 by Gibson assembly into the lentiviral transfer plasmid pL-SFFV.Reporter.RFP657.PAC, 659 a kind gift from Benjamin Ebert (Addgene plasmid \#61395). HEK-293FT cells were 660 seeded into a 6-well plate in $2 \mathrm{~mL}$ growth media (DMEM with 10\% (v/v) FBS, 100 units/mL 661 penicillin, and $0.1 \mathrm{mg} / \mathrm{mL}$ streptomycin) and were incubated at $37^{\circ} \mathrm{C}, 5 \% \mathrm{CO}$. Once cells 662 achieved $70-80 \%$ confluence approximately one day later, cells were transfected using 663 TransIT-LT1 (Mirus Bio) in Opti-MEM media (Life Technologies). TransIT-LT1 Reagent 664 was pre-warmed to room temperature and vortexed gently. For each well, $0.88 \mathrm{ug}$ 665 lentiviral transfer plasmid along with 0.66 ug pSPAX2 (Addgene plasmid \#12260) and 6660.44 ug pMD2.G (Addgene plasmid \#12259), kind gifts from Didier Trono, were added to $667250 \mu \mathrm{L}$ Opti-MEM media and mixed gently. TransIT-LT1 reagent (6 $\mu \mathrm{l})$ was added to the 668 DNA mixture, mixed gently, and incubated at room temperature for 15-20 minutes. The 669 mixture was added dropwise to different areas of the well. Plates were incubated at $37^{\circ} \mathrm{C}$, $6705 \% \mathrm{CO} 2 ;$ 48hrs later, the virus-containing media was collected and filtered with a $0.45 \mu \mathrm{m}$ 671 low protein-binding filter. HEK-Blue IL-18 cells (InvivoGen) were seeded into a 6-well 672 plate in $1 \mathrm{~mL}$ growth media (DMEM with 10\% (v/v) FBS, 100 units/mL penicillin, and 0.1 $673 \mathrm{mg} / \mathrm{mL}$ streptomycin) and $1 \mathrm{~mL}$ virus-containing media. Cells were incubated at $37^{\circ} \mathrm{C}, 5 \%$ 674 CO2 for two days before the media was changed.

676 Reporter cell stimulation and reading. Purified IgG titrations and 2 nM IL-33 were mixed 677 in $50 \mu \mathrm{L}$ assay media (DMEM with 10\% (v/v) FBS, 100 units $/ \mathrm{mL}$ penicillin, and $0.1 \mathrm{mg} / \mathrm{mL}$ 678 streptomycin) and incubated with shaking for 1 hour at room temperature. Approximately 67950,000 IL-33 reporter cells in $50 \mu \mathrm{L}$ assay media were added to wells of a sterile tissue 680 culture grade flat-bottom 96-well plate. IgG-IL-33 mixtures were added to respective wells 681 (1 nM IL-33 final concentration). Plates were incubated at $37^{\circ} \mathrm{C}, 5 \% \mathrm{CO} 2$ for 20 hours, 
682 then $20 \mu \mathrm{L}$ media from each well was added to $180 \mu \mathrm{L}$ room temperature QUANTI-Blue

683 Solution (InvivoGen) in a separate flat-bottom 96 -well plate and incubated at $37^{\circ} \mathrm{C}$ for 3

684 hours. Absorbance at $655 \mathrm{~nm}$ was measured in a Synergy HTX Multi-Mode Microplate

685 Reader (BioTek). Percent max signal was calculated based on signal generated by IL-33

686 in the absence of any serum.

688 ROC analysis of REAP score performance.

689 Orthogonal validation data for the receiver operator curve (ROC) analysis was obtained

690 by ELISA, LIPS, or clinical autoantibody tests. For ELISA and LIPS, valid reactivities were

691 defined as those 3 standard deviations above the healthy donor average for a given

692 protein in each assay. ROC analysis was performed using 247 test pairs across 25

693 different proteins. A full list of ROC inputs can be found in Supplementary Data 1.

694

695 Patient Samples

696 SLE patients. Collection of SLE patient blood samples was approved by the Yale Human

697 Research Protection Program Institutional Review Boards (protocol ID 1602017276). All

698 patients met the 2012 SLICC classification criteria for SLE ${ }^{63}$. Clinical information was

699 gathered via retrospective EMR review. Informed consent was obtained from all patients.

701 APECED patients. Collection of APECED patient blood samples was performed under a

702 NIAID IRB-approved prospective natural history study (11-I-0187, NCT01386437).

703 Patients underwent a comprehensive clinical evaluation at the NIH Clinical Center

704 including a detailed history and physical examination, laboratory and radiologic

705 evaluations and consultations by a multidisciplinary team of specialists including

706 infectious disease, immunology, genetics, endocrinology, gastroenterology, hepatology,

707 pulmonology, dermatology, dental, and ophthalmology, as previously described ${ }^{64}$. All

708 study participants provided written informed consent.

709

710 Statistical analysis.

711 Statistical details of experiments can be found in the figure legends. All REAP screens

712 and experimental assays were performed with technical replicates. Data analysis was 
713 performed using R, Python, Excel, and GraphPad Prism. Unless otherwise specified,

714 adjustment for false discovery rate was performed using the Benjamini-Hochberg

715 procedure.

716

717 Data Availability

718 Data are available from the corresponding author upon reasonable request.

720 Code Availability

721 All code will be available at GitHub.

\section{Figure Legends}

724 Figure 1: Yeast library and REAP development. a, Simplified schematic of REAP.

725 Antibodies are incubated with a genetically-barcoded yeast library displaying members of

726 the exoproteome in 96-well microtiter plates. Antibody bound yeast are enriched by

727 magnetic column-based sorting and enrichment is quantified by next-generation

728 sequencing. $\mathbf{b}$, Composition of proteins in the yeast library, categorized by broad protein

729 families. Abbreviations are as follows: immunoglobulin superfamily (IgSF), epidermal

730 growth factor (EGF), fibronectin (Fn), leucine-rich repeat (LRR), urokinase receptor

731 (UPAR), c-type lectin (CLEC), tetraspanin (TSPAN). The cytokine family consists of

732 proteins belonging to tumor necrosis factor, interferon, interleukin, and growth factor

733 protein families. $\mathbf{c}$ \& d, Distribution of total protein frequencies (c) and unique yeast clones

734 per protein in the yeast library (d). Solid lines indicate the median of the distribution and

735 dotted lines indicate first and third quartiles.

737 Figure 2: Validation of REAP. A panel of nine monoclonal antibodies were screened 738 using REAP. a, Heatmap of results from REAP screen of nine monoclonal antibodies.

739 Only relevant monoclonal antibody targets (gene names) are displayed. b,

740 Representative sample from the screen. Monoclonal antibody target is highlighted in red

741 and labelled. Background subtraction was performed by subtracting the score of a 742 selection performed with beads and secondary alone. Scores below the average 
743 background level are not shown. c, REAP screen performed using recombinant protein

744 in place of $\lg$.

746 Figure 3: REAP screen of APECED patients. A cohort of 77 APECED patients and 20 747 healthy controls were screened using REAP. a, Heatmap of REAP scores. Antigen 748 groups were manually categorized. b, Frequencies of positive reactivities (score $\geq$ healthy 749 donor average score plus 3 standard deviations) against 14 antigens based on REAP 750 and prior literature ${ }^{18,43,47}$. c, Violin plot of GIF REAP scores in APECED samples stratified 751 by intrinsic factor clinical autoantibody test results. d, EC50 of fitted REAP and ELISA 752 dose response curves for detection of autoantibodies against four proteins in one 753 APECED patient. See supplementary figure 1e,f for dose response curves. e, Violin 754 plot of the number of reactivities in APECED and control samples at a score cutoff of 3. 755 f, anti-GPHB5 and $\mathbf{g}$, anti-PNLIP pan-IgG ELISAs conducted with serial dilutions of 756 serum. Error bars represent standard deviation. $\mathbf{h}$, Heatmap of LCN1 and BPIFA1 REAP 757 scores in APECED samples stratified by pneumonitis positivity. Listed p-values represent 758 significance for the association between LCN1 or BPIFA1 REAP positivity and 759 pneumonitis. Significance in $\mathbf{c}$ and $\mathbf{e}$ was determined using a two-sided Mann-Whitney $U$ 760 test. Significance in $\mathbf{h}$ was determined using a Fisher Exact Test, where LCN1 and 761 BPIFA1 positivity was defined by a REAP score $\geq 3$. In all heatmaps in this figure, score 762 was artificially capped at 7 to aid visualization. In all violin plots in this figure, solid lines 763 represent the median and dotted lines represent the first or third quartile. ${ }^{* * *} \mathrm{P} \leq 0.0001$

765 Figure 4: REAP screen of SLE patients. A cohort of 106 unique SLE patients spanning 766155 samples and 20 healthy controls was screened using REAP. a, Heatmap of REAP 767 scores where each column is a unique patient. For patients with longitudinal samples, the 768 maximum REAP score for each given reactivity is shown. Antigen groups were manually 769 categorized. Patients are ordered from left to right by increasing SLEDAI score. White 770 stars symbolize detection of a therapeutic antibody. Score was artificially capped at 7 to 771 aid visualization. b, Violin plots of the number of reactivities in SLE samples stratified by 772 disease severity and control samples at a score cutoff of 3 . Significance was determined 773 using a Kruskal-Wallis test followed by a Dunnett's test. c, Heatmap of false discovery 
774 rate-adjusted p-values from two-sided Mann-Whitney $U$ tests comparing REAP score

775 distributions for specific proteins between patients stratified by disease manifestations.

776 Only reactivities positive in at least 3 patients were tested. d, SLEDAI scores for SLE

777 patients stratified by reactivity against CCL8. e, SLEDAI scores for SLE patients positive

778 or negative by REAP score for reactivities against immunoregulatory antigens (defined in

779 a). f, anti-PD-L2 and i, anti-IL-33 pan-IgG ELISAs conducted with serial dilutions of SLE

780 or control serum. $\mathbf{g}$, schematic and $\mathbf{h}$, results of PD-L2 blocking assay conducted with 781 serial dilutions of serum from a control and the SLE patient in $\mathbf{f}$. j, schematic and $\mathbf{k}$, results

782 of IL-33 neutralization assay conducted with serial dilutions of IgG from a control and the

783 SLE patient in i. Significance in $\mathbf{d}$ and $\mathbf{e}$ was determined using a two-sided Mann-Whitney

$784 U$ test. All error bars in this figure represent standard deviation. For all analyses in this

785 figure, positive reactivities were defined as those with REAP score $\geq 3$. ${ }^{*} \mathrm{P} \leq 0.05,{ }^{*} \mathrm{P} \leq$ 7860.01.

Table 1: Orthogonal validation of SLE autoantibody reactivities identified in

789 REAP.

Supplementary Figure 1: Exoproteome yeast display library properties. a, Flowchart

792 of steps in identification and annotation of extracellular or secreted proteins for inclusion

793 in the library. b, Pie chart of all extracellular or secreted proteins identified in a. Proteins

794 were not attempted if they had an ectodomain less than 50 amino acids or less than 600

795 amino acids. c, Percent of proteins displayed in each protein family included in the library.

796 The dotted line represents the aggregate display level in the library. Abbreviations are as

797 follows: immunoglobulin superfamily (IgSF), epidermal growth factor (EGF), fibronectin

$798(F n)$, leucine-rich repeat (LRR), urokinase receptor (UPAR), c-type lectin (CLEC),

799 tetraspanin (TSPAN). The cytokine family consists of proteins belonging to tumor necrosis

800 factor, interferon, interleukin, and growth factor protein families. d, Box plot of Log $2[$ fold

801 enrichment] $R^{2}$ coefficient of determination values between technical replicates of

802 APECED patients screened in figure 2. e \& f, REAP (e) versus ELISA (f) dose-response

803 curve comparison for APECED autoantibodies against four proteins. REAP data is from

804 a screen conducted using varying concentrations of AIRE.19 lgG. Curves were fit using 
805 a sigmoidal 4 parameter logistic curve. For REAP, curves were fit based on Log 2 [fold 806 enrichment]. For ELISA, curves were fit based on optical density at $450 \mathrm{~nm}$. Error bars 807 represent standard error of the mean. $\mathbf{g}$, Comparison of autoantibody detection 808 frequencies in APECED patient cohorts by REAP, LIPS ${ }^{18}$, ProtoArray ${ }^{18}$, and PhIP-Seq ${ }^{21}$. 809 Frequencies are listed as a percentage inside each circle. Size and color of circles are 810 proportional to detection frequency. For REAP, detection frequency was calculated as in

811 figure 2b. For LIPS and ProtoArray, detection frequencies were provided in the 812 corresponding publication. For PhIP-Seq, detection frequency was calculated based on 813 figures in the corresponding publication. For reactivities labelled n.d., either data was not 814 publicly available or the autoantibody was not tested for in the corresponding assay.

816 Supplementary Figure 2: APECED and SLE reactivity distributions. a, Violin plots of 817 the number of reactivities in APECED and control samples at a score cutoff of 1 or 2 . b, 818 Mean number of reactivities in APECED and control samples at various score cutoffs, 819 along with indicators of significance. c, Violin plots of the number of reactivities in SLE 820 samples stratified by disease severity and control samples at a score cutoff of 1 or 2 . d, 821 Mean number of reactivities in SLE samples stratified by disease severity and control 822 samples at various score cutoffs. Comparisons were made between each disease 823 severity group and the control group. Significance in $\mathbf{a}$ and $\mathbf{b}$ was calculated using a two824 sided Mann-Whitney $U$ test. Significance in $\mathbf{c}$ and $\mathbf{d}$ was determined using a Kruskal825 Wallis test followed by a Dunnett's test.

827 Supplementary Figure 3: REAP validation and ROC analysis. a-I, Single-point ELISAs 828 or LIPS conducted with SLE, APECED, or control serum to detect autoantibodies against 829 ACVR2B (a), CCL8 (b), CSPG5 (c), CXCL3 (d), Fas (e), IL-4 (f), IL-6 (g), IL-16 (h), IL-22 830 (i), IFN- $\alpha 8(\mathbf{j})$, IFN- $\alpha 7(\mathbf{k})$, and IFNL2 (I). Serum dilutions are listed in the title of each plot. 831 m-r, ELISAs or LIPS conducted with serial dilutions of SLE, APECED, or control serum 832 to detect autoantibodies against BPIFA2 (m), EPYC (n), IER3 (o), IL18RAP (p), LILRB4 833 (q), and VEGF-B (r). Dotted lines in a-I represent the control average + 3 standard 834 deviations. s, Receiver operating characteristic curve of the ability of REAP score to 835 predict validation of a REAP reactivity in an orthogonal assay. A full description of this 
836 analysis can be found in the materials and methods section. $t$, Anti-epiphycan IgG

837 subclass specific ELISA conducted with serial dilutions of serum from the SLE patient

838 with highest titers in $\mathbf{n}$. $\mathbf{u}$, Anti-IL-18RAcP subclass specific ELISA conducted with serial

839 dilutions of serum from the SLE patient in p. v, Anti-PD-L2 IgG subclass specific ELISAs

840 conducted with serial dilutions of serum from the SLE patient in figure $3 \mathbf{f}$. All error bars

841 in this figure all represent standard deviation. All curves in this figure were fit using a

842 sigmoidal 4 parameter logistic curve.

843

844 Supplementary Table 1: List of protein antigens included in library

845

846 Supplementary Table 2: APECED patient demographics and clinical

847 characteristics.

848

849 Supplementary Table 3: SLE patient and control demographics and clinical

850 characteristics.

851

852 Supplementary Data 1: Receiver operating characteristic analysis inputs

853

854 References

855 1. Ludwig, R. J. et al. Mechanisms of Autoantibody-Induced Pathology. Front. Immunol.

856 8, 603 (2017).

857 2. Kazarian, M. \& Laird-Offringa, I. A. Small-cell lung cancer-associated autoantibodies:

858 potential applications to cancer diagnosis, early detection, and therapy. Mol. Cancer

$85910,33(2011)$.

860 3. Leslie, R. D., Palmer, J., Schloot, N. C. \& Lernmark, A. Diabetes at the crossroads:

861 relevance of disease classification to pathophysiology and treatment. Diabetologia

$862 \quad 59,13-20(2016)$.

863 4. Menconi, F., Marcocci, C. \& Marinò, M. Diagnosis and classification of Graves' 864 disease. Autoimmun. Rev. 13, 398-402 (2014).

865 5. Meier, L. A. \& Binstadt, B. A. The Contribution of Autoantibodies to Inflammatory 866 Cardiovascular Pathology. Front. Immunol. 9, 911 (2018). 
867 6. Ercolini, A. M. \& Miller, S. D. The role of infections in autoimmune disease. Clin. Exp. Immunol. 155, 1-15 (2009).

7. De Virgilio, A. et al. Parkinson's disease: Autoimmunity and neuroinflammation. Autoimmun. Rev. 15, 1005-1011 (2016).

8. Britschgi, M. et al. Neuroprotective natural antibodies to assemblies of amyloidogenic peptides decrease with normal aging and advancing Alzheimer's disease. Proc. Natl. Acad. Sci. U. S. A. 106, 12145-12150 (2009).

9. Cappellano, G. et al. Anti-cytokine autoantibodies in autoimmune diseases. Am. J. Clin. Exp. Immunol. 1, 136-146 (2012).

10. Watanabe, M., Uchida, K., Nakagaki, K., Trapnell, B. C. \& Nakata, K. High avidity cytokine autoantibodies in health and disease: pathogenesis and mechanisms. Cytokine Growth Factor Rev. 21, 263-273 (2010).

11. Tabuchi, Y. et al. Protective effect of naturally occurring anti-HER2 autoantibodies on breast cancer. Breast Cancer Res. Treat. 157, 55-63 (2016).

12. Gillissen, M. A. et al. Patient-derived antibody recognizes a unique CD43 epitope expressed on all AML and has antileukemia activity in mice. Blood Adv 1, 1551-1564 (2017).

13. von Mensdorff-Pouilly, S. et al. Survival in early breast cancer patients is favorably influenced by a natural humoral immune response to polymorphic epithelial mucin. J. Clin. Oncol. 18, 574-583 (2000).

14. Naparstek, Y. \& Plotz, P. H. The Role of Autoantibodies in Autoimmune Disease. (2003) doi:10.1146/annurev.iy.11.040193.000455.

15. Larman, H. B. et al. Autoantigen discovery with a synthetic human peptidome. Nat. Biotechnol. 29, 535-541 (2011).

16. Larman, H. B. et al. PhIP-Seq characterization of autoantibodies from patients with

894 17. Benjamin Larman, H. et al. Cytosolic 5'-nucleotidase 1A autoimmunity in sporadic 895 inclusion body myositis: cN1A Autoimmunity in IBM. Ann. Neurol. 73, 408-418 $896 \quad$ (2013). 
18. Meyer, S. et al. AIRE-Deficient Patients Harbor Unique High-Affinity DiseaseAmeliorating Autoantibodies. Cell 166, 582-595 (2016).

19. Landegren, N. et al. Proteome-wide survey of the autoimmune target repertoire in autoimmune polyendocrine syndrome type 1. Sci. Rep. 6, 20104 (2016).

20. Fishman, D. et al. Autoantibody Repertoire in APECED Patients Targets Two Distinct Subgroups of Proteins. Front. Immunol. 8, 976 (2017).

21. Vazquez, S. E. et al. Identification of novel, clinically correlated autoantigens in the monogenic autoimmune syndrome APS1 by proteome-wide PhIP-Seq. Elife 9, (2020).

906

22. Kamath, K. et al. Antibody epitope repertoire analysis enables rapid antigen discovery and multiplex serology. Sci. Rep. 10, 5294 (2020).

23. Chen, W. S. et al. Autoantibody Landscape in Patients with Advanced Prostate Cancer. Clin. Cancer Res. 26, 6204-6214 (2020).

24. Laver, W. G., Air, G. M., Webster, R. G. \& Smith-Gill, S. J. Epitopes on protein antigens: misconceptions and realities. Cell 61, 553-556 (1990).

25. Gai, S. A. \& Wittrup, K. D. Yeast surface display for protein engineering and characterization. Curr. Opin. Struct. Biol. 17, 467-473 (2007).

26. Weiskopf, K. et al. Engineered SIRPa variants as immunotherapeutic adjuvants to anticancer antibodies. Science 341, 88-91 (2013).

27. Warren, J. T. et al. Manipulation of receptor oligomerization as a strategy to inhibit signaling by TNF superfamily members. Sci. Signal. 7, ra80 (2014).

28. Schweickhardt, R. L., Jiang, X., Garone, L. M. \& Brondyk, W. H. Structure-Expression Relationship of Tumor Necrosis Factor Receptor Mutants That Increase Expression*. J. Biol. Chem. 278, 28961-28967 (2003).

29. Jin, M. et al. Directed evolution to probe protein allostery and integrin I domains of 200,000-fold higher affinity. Proc. Natl. Acad. Sci. U. S. A. 103, 5758-5763 (2006).

30. Chen, T. F., de Picciotto, S., Hackel, B. J. \& Wittrup, K. D. Engineering fibronectin925 based binding proteins by yeast surface display. Methods Enzymol. 523, 303-326 (2013).

31. Xu, G., Tasumi, S. \& Pancer, Z. Yeast surface display of lamprey variable lymphocyte receptors. Methods Mol. Biol. 748, 21-33 (2011). 
928 32. Chao, G., Cochran, J. R. \& Wittrup, K. D. Fine epitope mapping of anti-epidermal growth factor receptor antibodies through random mutagenesis and yeast surface display. J. Mol. Biol. 342, 539-550 (2004).

33. Jeong, M.-Y., Rutter, J. \& Chou, D. H.-C. Display of Single-Chain Insulin-like Peptides on a Yeast Surface. Biochemistry 58, 182-188 (2019).

933 34. Levin, A. M. et al. Exploiting a natural conformational switch to engineer an 934 interleukin-2 "superkine." Nature 484, 529-533 (2012).

35. Zhou, T. et al. IL-18BP is a secreted immune checkpoint and barrier to IL-18 immunotherapy. Nature 583, 609-614 (2020).

36. Ho, C. C. M. et al. Decoupling the Functional Pleiotropy of Stem Cell Factor by Tuning c-Kit Signaling. Cell 168, 1041-1052.e18 (2017).

37. Boder, E. T., Bill, J. R., Nields, A. W., Marrack, P. C. \& Kappler, J. W. Yeast surface display of a noncovalent MHC class II heterodimer complexed with antigenic peptide. Biotechnol. Bioeng. 92, 485-491 (2005).

38. Birnbaum, M. E. et al. Deconstructing the peptide-MHC specificity of $T$ cell recognition. Cell 157, 1073-1087 (2014).

39. Kieke, M. C. et al. Selection of functional T cell receptor mutants from a yeast surfacedisplay library. Proc. Natl. Acad. Sci. U. S. A. 96, 5651-5656 (1999).

40. Rhiel, L. et al. REAL-Select: full-length antibody display and library screening by surface capture on yeast cells. PLoS One 9, e114887 (2014).

41. Boder, E. T. \& Wittrup, K. D. Yeast surface display for screening combinatorial polypeptide libraries. Nat. Biotechnol. 15, 553-557 (1997).

42. Constantine, G. M. \& Lionakis, M. S. Lessons from primary immunodeficiencies: Autoimmune regulator and autoimmune polyendocrinopathy-candidiasis-ectodermal dystrophy. Immunol. Rev. 287, 103-120 (2019).

43. Meager, A. et al. Anti-interferon autoantibodies in autoimmune polyendocrinopathy syndrome type 1. PLoS Med. 3, e289 (2006).

955 44. Wolff, A. S. B. et al. Autoimmune polyendocrine syndrome type 1 in Norway: 956 phenotypic variation, autoantibodies, and novel mutations in the autoimmune 957 regulator gene. J. Clin. Endocrinol. Metab. 92, 595-603 (2007). 
958

959

960

961

962

963

964

965

966

967

968

969

970

971

972

973

974

975

976

977

978

979

980

981

982

983

984

985

986

987

988

45. Meloni, A. et al. Autoantibodies against type I interferons as an additional diagnostic criterion for autoimmune polyendocrine syndrome type I. J. Clin. Endocrinol. Metab. 93, 4389-4397 (2008).

46. Puel, A. et al. Autoantibodies against IL-17A, IL-17F, and IL-22 in patients with chronic mucocutaneous candidiasis and autoimmune polyendocrine syndrome type I. J. Exp. Med. 207, 291-297 (2010).

47. Kisand, K. et al. Chronic mucocutaneous candidiasis in APECED or thymoma patients correlates with autoimmunity to Th17-associated cytokines. J. Exp. Med. 207, 299-308 (2010).

48. Burbelo, P. D. et al. Profiling Autoantibodies against Salivary Proteins in Sicca Conditions. J. Dent. Res. 98, 772-778 (2019).

49. St-Pierre, C., Trofimov, A., Brochu, S., Lemieux, S. \& Perreault, C. Differential Features of AIRE-Induced and AIRE-Independent Promiscuous Gene Expression in Thymic Epithelial Cells. J. Immunol. 195, 498-506 (2015).

50. Ferré, E. M. N. et al. Lymphocyte-driven regional immunopathology in pneumonitis caused by impaired central immune tolerance. Sci. Transl. Med. 11, (2019).

51. Lowe, M. E. STRUCTURE AND FUNCTION OF PANCREATIC LIPASE AND COLIPASE. (2003) doi:10.1146/annurev.nutr.17.1.141.

52. Tsokos, G. C., Lo, M. S., Costa Reis, P. \& Sullivan, K. E. New insights into the immunopathogenesis of systemic lupus erythematosus. Nat. Rev. Rheumatol. 12, 716-730 (2016).

53. Pisetsky, D. S. \& Lipsky, P. E. New insights into the role of antinuclear antibodies in systemic lupus erythematosus. Nat. Rev. Rheumatol. 16, 565-579 (2020).

54. Bombardier, C., Gladman, D. D., Urowitz, M. B., Caron, D. \& Chang, C. H. Derivation of the SLEDAI. A disease activity index for lupus patients. The Committee on Prognosis Studies in SLE. Arthritis Rheum. 35, 630-640 (1992).

55. Yang, Z., Liang, Y., Xi, W., Li, C. \& Zhong, R. Association of increased serum IL-33 levels with clinical and laboratory characteristics of systemic lupus erythematosus in Chinese population. Clin. Exp. Med. 11, 75-80 (2011).

56. Guo, J. et al. The association of novel IL-33 polymorphisms with sIL-33 and risk of systemic lupus erythematosus. Mol. Immunol. 77, 1-7 (2016). 
57. Rose, W. A., 2nd et al. Interleukin-33 Contributes Toward Loss of Tolerance by Promoting B-Cell-Activating Factor of the Tumor-Necrosis-Factor Family (BAFF)Dependent Autoantibody Production. Front. Immunol. 9, 2871 (2018).

58. Li, P., Lin, W. \& Zheng, X. IL-33 neutralization suppresses lupus disease in lupusprone mice. Inflammation 37, 824-832 (2014).

994 59. Herscovics, A. \& Orlean, P. Glycoprotein biosynthesis in yeast. FASEB J. 7, 540-550 (1993).

60. Hamilton, S. R. \& Gerngross, T. U. Glycosylation engineering in yeast: the advent of fully humanized yeast. Curr. Opin. Biotechnol. 18, 387-392 (2007).

61. Picelli, S. et al. Tn5 transposase and tagmentation procedures for massively scaled sequencing projects. Genome Res. 24, 2033-2040 (2014).

1000

62. Robinson, M. D., McCarthy, D. J. \& Smyth, G. K. edgeR: a Bioconductor package for differential expression analysis of digital gene expression data. Bioinformatics 26, 139-140 (2010).

1003

63. Petri, M. et al. Derivation and validation of the Systemic Lupus International Collaborating Clinics classification criteria for systemic lupus erythematosus. Arthritis Rheum. 64, 2677-2686 (2012).

64. Ferre, E. M. N. et al. Redefined clinical features and diagnostic criteria in autoimmune polyendocrinopathy-candidiasis-ectodermal dystrophy. JCI Insight 1, (2016).

\section{Acknowledgements}

1010 The authors gratefully acknowledge all members of the Ring Laboratory and Daniela 1011 Deny for helpful advice and technical assistance. The authors also thank the Yale Section 1012 of Rheumatology, Allergy \& Immunology for providing systemic lupus erythematosus 1013 (SLE) samples from its repository as well as the members of the Yale Rheumatology 1014 Clinical and Translational Research Laboratory, Shannon Teaw BS and Michelle Cheng 1015 BA for aliquoting SLE patient sera. This work was supported by gifts from the Mathers 1016 Family Foundation, the Colton Foundation, the Ludwig Family Foundation, and a 1017 supplement to the Yale Cancer Center Support Grant 3P30CA016359-40S4. A.M.R. is 1018 additionally supported by an NIH Director's Early Independence Award (DP5OD023088), 1019 a Pew-Stewart Award, and the Robert T. McCluskey Foundation. This work was 
1020 supported by the Division of Intramural Research of the National Institute of Allergy and 1021 Infectious Diseases, NIH.

1022

\section{Author Contributions}

1024 E.Y.W., Y.D., C.E.R., F.L., and Y.Y. performed experiments. M.X.D. provided lupus 1025 patient samples and clinical annotations. M.M.S., E.M.N.F., and M.S.L. provided 1026 APECED patient samples and clinical annotations. E.Y.W., Y.D., E.M., M.S.L., and 1027 A.M.R. analyzed data, M.H., M.S.L., and A.M.R. provided project supervision. E.Y.W. and 1028 A.M.R. wrote the paper.

1029

\section{Competing Interests}

1031 E.Y.W., Y.D., C.E.R., and A.M.R. are inventors of a patent describing the REAP 1032 technology and A.M.R. is the founder of Seranova Bio. 

bioRxiv preprint dol: https://doi.org/10.1101/2021.02.11.430703; this version posted March 21, 2021. The copyright holder for this preprint
(which was not certified by peer review) is the author/funder, who has granted bioRxiv a license to display the preprint in perpetuity. It is made
available under aCC-BY-NC-ND 4 O International license

Figure 1
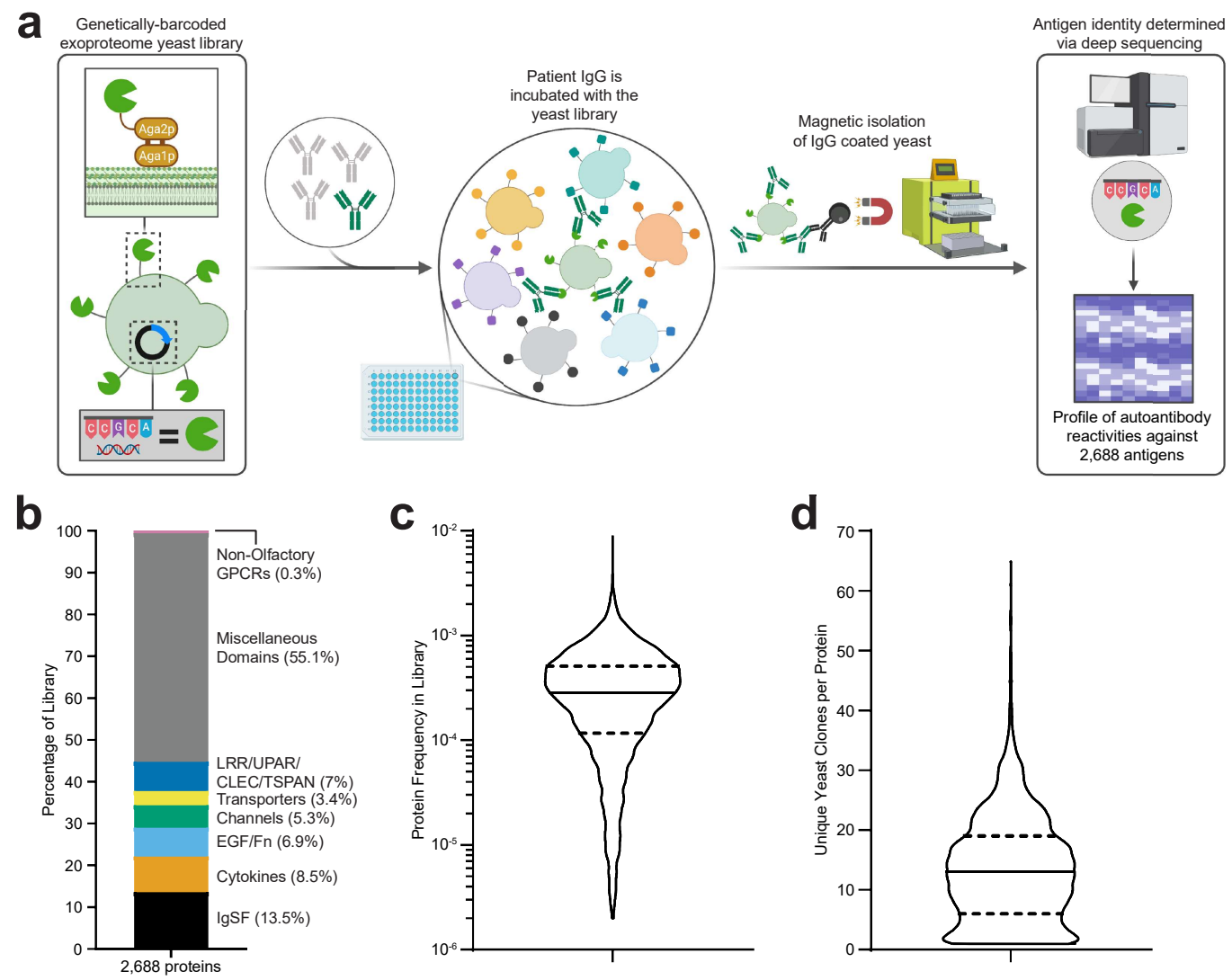
bioRxiv preprint doi: https://doi org/10.1101/2021.0211.430703; this version posted March 21, 2021. The copyright holder for this preprint (which was not certified by peer review) is the author/funder, who has granted bioRxiv a license to display the preprint in perpetuity. It is made available under aCC-BY-NC-ND 4.0 International license.

\section{Figure 2}

a

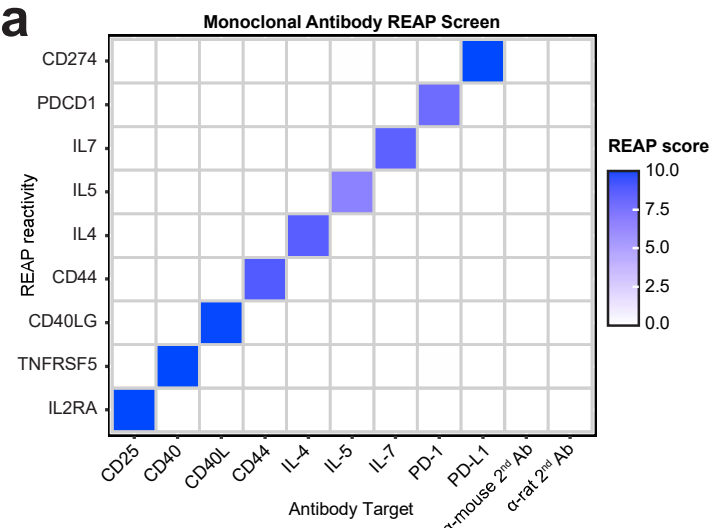

b anti-CD25 monoclonal REAP result

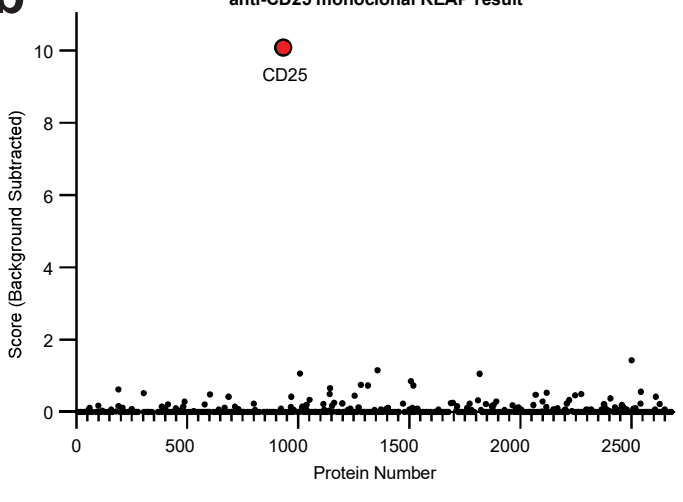

C

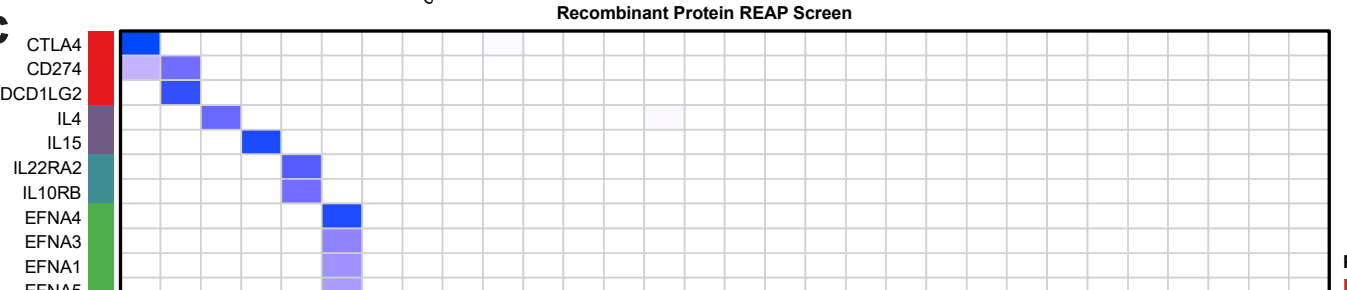

EFNA1

EFNA5

EFNA2

EFNB2
EPHB2

EPHA5

$$
\begin{aligned}
& \text { EPHA7 } \\
& \text { EPHA2 }
\end{aligned}
$$$$
\text { EPHA2 }
$$

EPHA4
CSF2
FGF20

$\sum_{\bar{d}}$ FGF2

崖 FGF4

$\underset{\varpi}{W G F 16}$

FGF18

FGFR

FGFR3
EPOR

EPOR
IL28B

IFNL2

IFNAR2
RAET1L

RAET1L
RAET1E

RAET
MICA

ULBP1

ULBP2

ULBP3

SIRPA

CD48

TNFSF9

TNFRSF9
PGLYRP1

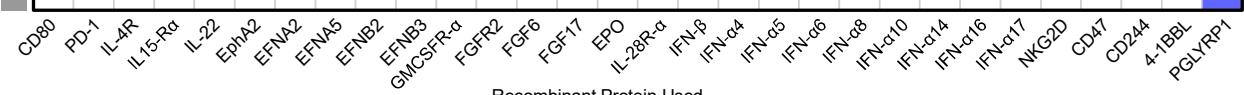

Protein Family

B7 family

cytokine

cytokine receptor

ephrin

ephrin receptor

growth factor

growth factor receptor

interferon

interferon receptor

MHC class I superfamily

SIRP family

SLAM family

TNF superfamily

REAP score

10.0

$-7.5$

5.0

25 
bioRxiv preprint doi: https://doi.org/10.1101/2021.02 11.430703; this version posted March 21, 2021. The copyright holder for this preprint (which was not certified by peer review) is the author/funder, who has granted bioRxiv a license to display the preprint in perpetuity. It is made available under aCC-BY-NC-ND 4.0 International license.

Figure 3

$\mathbf{a}_{\text {IENAB }}$ APECED
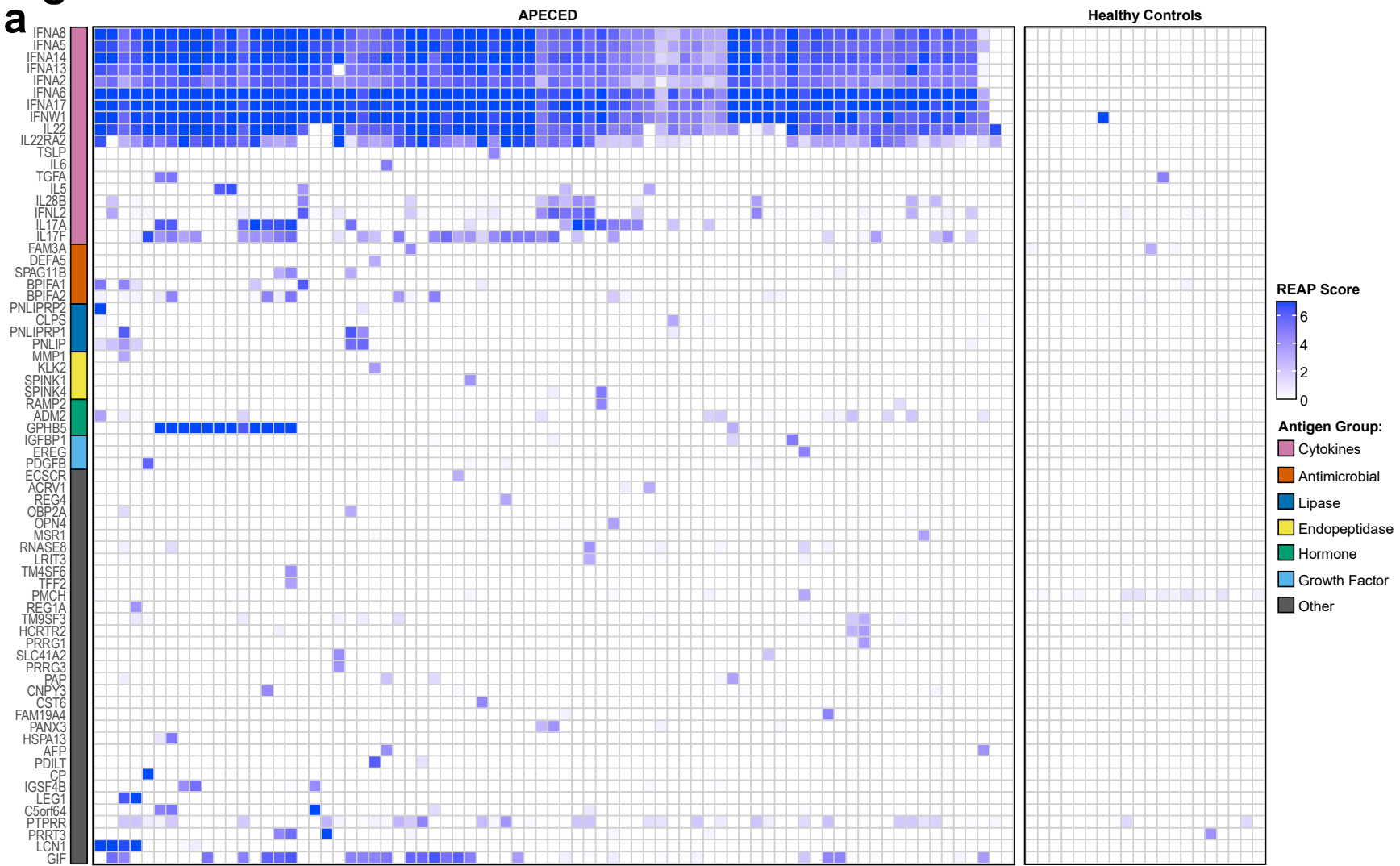

\begin{tabular}{|c|c|c|}
\hline Antigen & $\begin{array}{c}\text { REAP } \\
\text { Frequency }\end{array}$ & $\begin{array}{l}\text { Reported } \\
\text { Frequency }\end{array}$ \\
\hline IFN- $\alpha 2$ & 97.4 & $100^{18.43}$ \\
\hline IFN-a5 & 97.4 & $100^{18}$ \\
\hline IFN-a6 & 98.7 & $100^{18}$ \\
\hline $\mathrm{IFN}-\alpha 8$ & 97.4 & $100^{18}$ \\
\hline IFN-a13 & 98.7 & $100^{18}$ \\
\hline IFN- $\alpha 14$ & 97.4 & $100^{18}$ \\
\hline IFN- $\alpha 17$ & 97.4 & $100^{18}$ \\
\hline IFN- $\omega$ & 83.1 & $100^{18,43}$ \\
\hline $1 \mathrm{FN}-\lambda 2$ & 22.1 & $28^{18}$ \\
\hline $\mid \mathrm{FN}-\lambda 3$ & 19.5 & $28^{18}$ \\
\hline IL-22 & 97.4 & $91^{47}, 94^{18}$ \\
\hline IL-17A & 27.27 & $35^{18}, 41^{47}$ \\
\hline LL-17F & 58.4 & $70^{18}, 75^{47}$ \\
\hline IL-5 & 9.1 & $16^{18}$ \\
\hline
\end{tabular}
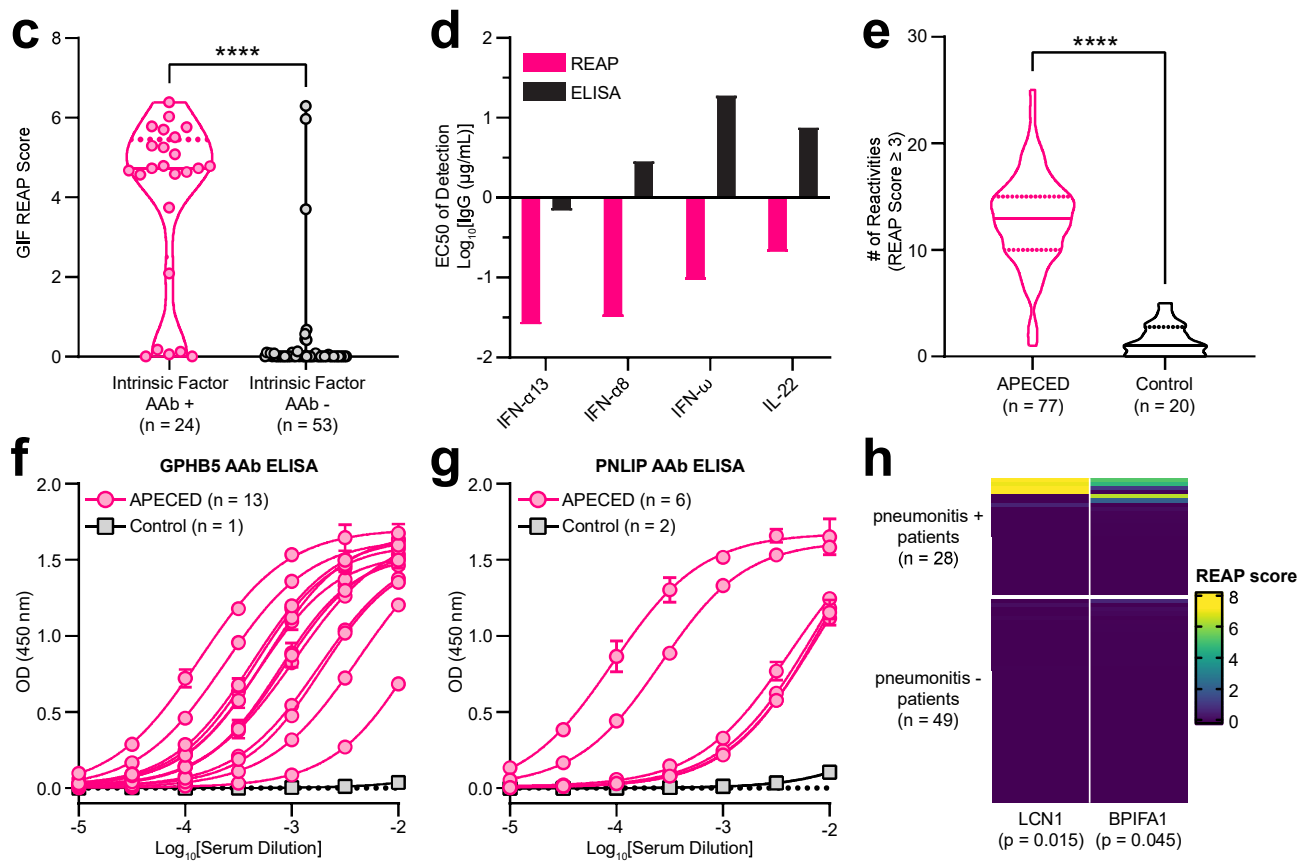
bioRxiv preprint doi: https://doi.org/10.1101/2021.02.11.430703; this version posted March 21, 2021. The copyright holder for this preprint (which was not certified by peer review) is the author/funder, who has granted bioRxiv a license to display the preprint in perpetuity. It is made available under aCC-BY-NC-ND 4.0 International license.

Figure 4
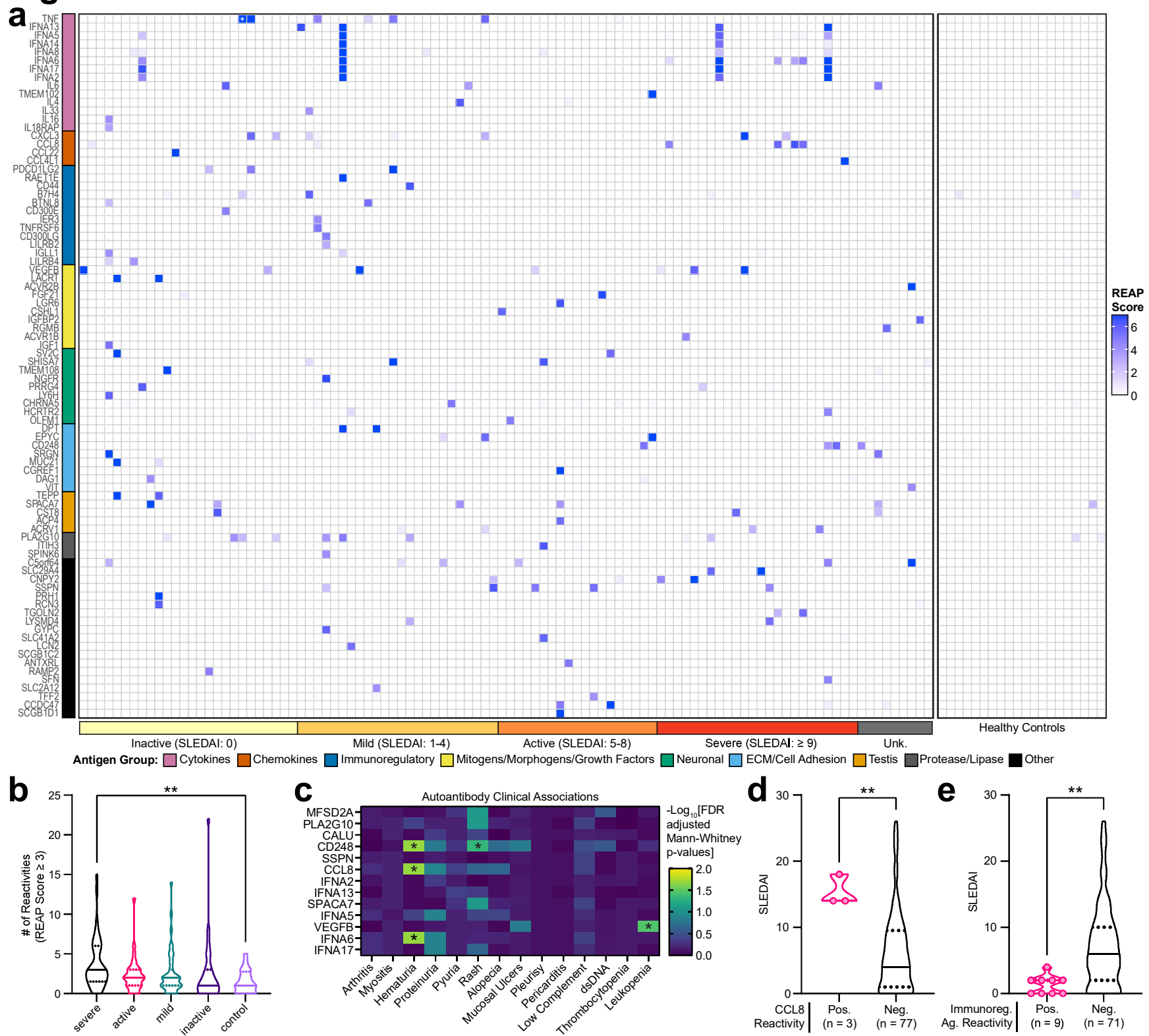

C

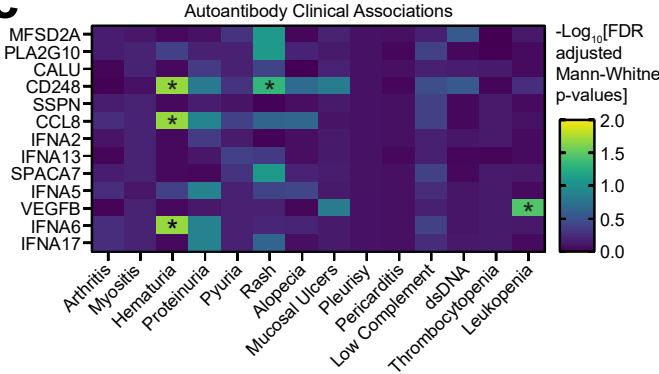

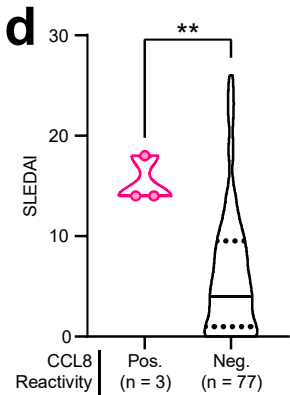

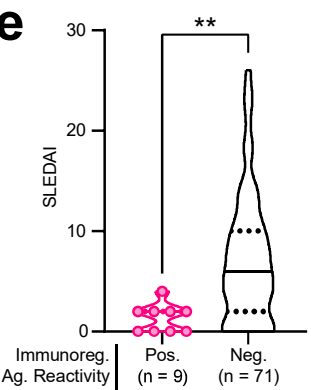

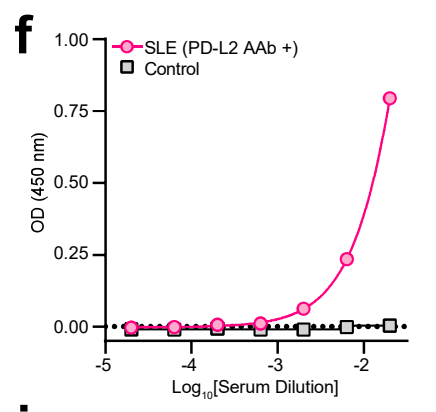

i

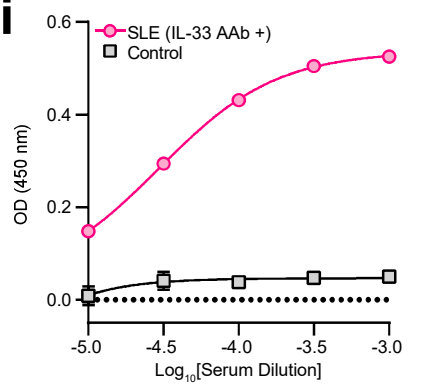

g
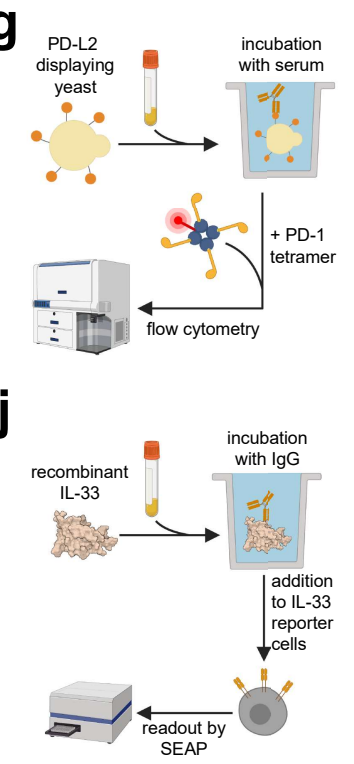

$\mathbf{h}$

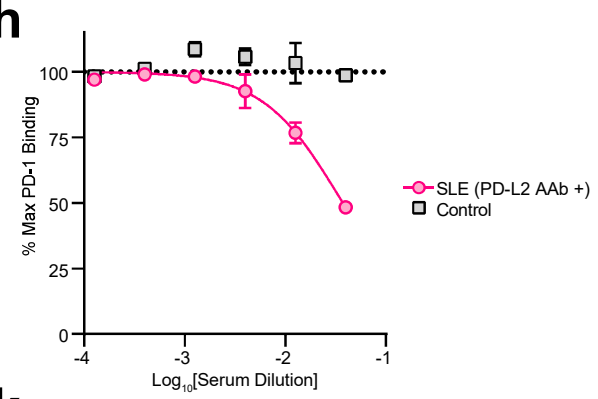

k

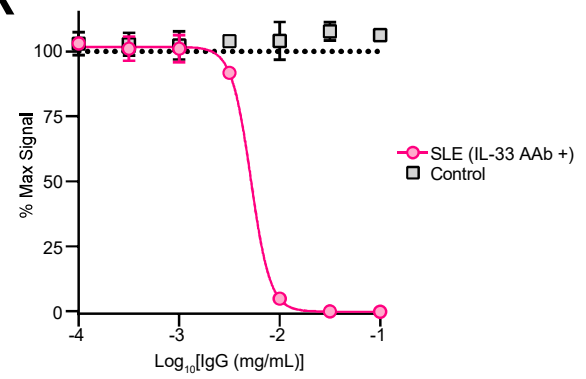


bioRxiv preprint doi: https://doi.org/10.1101/2021.02.11.430703; this version posted March 21, 2021. The copyright holder for this preprint (which was not certified by peer review) is the author/funder, who has granted bioRxiv a license to display the preprint in perpetuity. It is made available under aCC-BY-NC-ND 4.0 International license.

\section{Table 1}

Table 1 | Orthogonal validation of SLE autoantibody reactivities identified in REAP.

\begin{tabular}{|c|c|c|c|}
\hline Antigen & $\begin{array}{c}\text { \# Candidate } \\
\text { Samples } \\
\text { Tested }\end{array}$ & $\begin{array}{c}\text { REAP Score } \\
\text { Range }\end{array}$ & $\begin{array}{c}\text { \# Validated } \\
\text { by ELISA or } \\
\text { LIPS }\end{array}$ \\
\hline VEGF-B & 10 & $1.67-8.88$ & 10 \\
\hline IFN- $\alpha 17$ & 8 & $1.85-10.33$ & 8 \\
\hline IFN- $\alpha 8$ & 7 & $1.13-8.92$ & 4 \\
\hline FAS & 6 & $1.73-4.95$ & 4 \\
\hline EPYC & 4 & $4.93-9.46$ & 4 \\
\hline CSPG5 & 6 & $1.64-5.92$ & 3 \\
\hline IL-6 & 3 & $3.60-7.82$ & 3 \\
\hline PD-L2 & 4 & $2.43-9.69$ & 2 \\
\hline IL-4 & 2 & $5.78-6.09$ & 2 \\
\hline CCL8 & 4 & $4.59-6.44$ & 1 \\
\hline IL-33 & 1 & 3.88 & 1 \\
\hline IL-18R $\beta$ & 1 & 3.3 & 1 \\
\hline IL-16 & 1 & 4.03 & 1 \\
\hline LILRB4 & 1 & 3.85 & 1 \\
\hline ACVR2B & 1 & 8.56 & 1 \\
\hline IER3 & 1 & 4.23 & 1 \\
\hline IFNL2 & 6 & $3.27-7.74$ & 0 \\
\hline NGFR & 4 & $3.40-6.73$ & 0 \\
\hline RGMB & 4 & $4.15-5.49$ & 0 \\
\hline CD44 & 1 & 6.34 & 0 \\
\hline RAET1E & 1 & 7.6 & 0 \\
\hline
\end{tabular}


bioRxiv preprint doi: https://doi.org/10.1101/2021.02.11.430703; this version posted March 21, 2021. The copyright holder for this preprint (which was not certified by peer review) is the author/funder, who has granted bioRxiv a license to display the preprint in perpetuity. It is made available under aCC-BY-NC-ND 4.0 International license.

\section{Supplementary Figure 1}

a

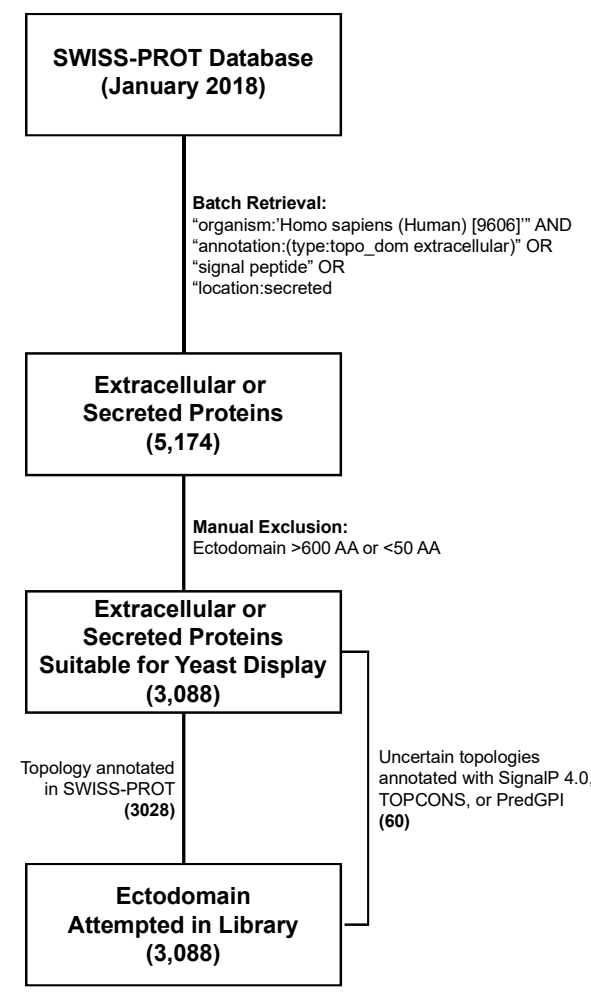

b
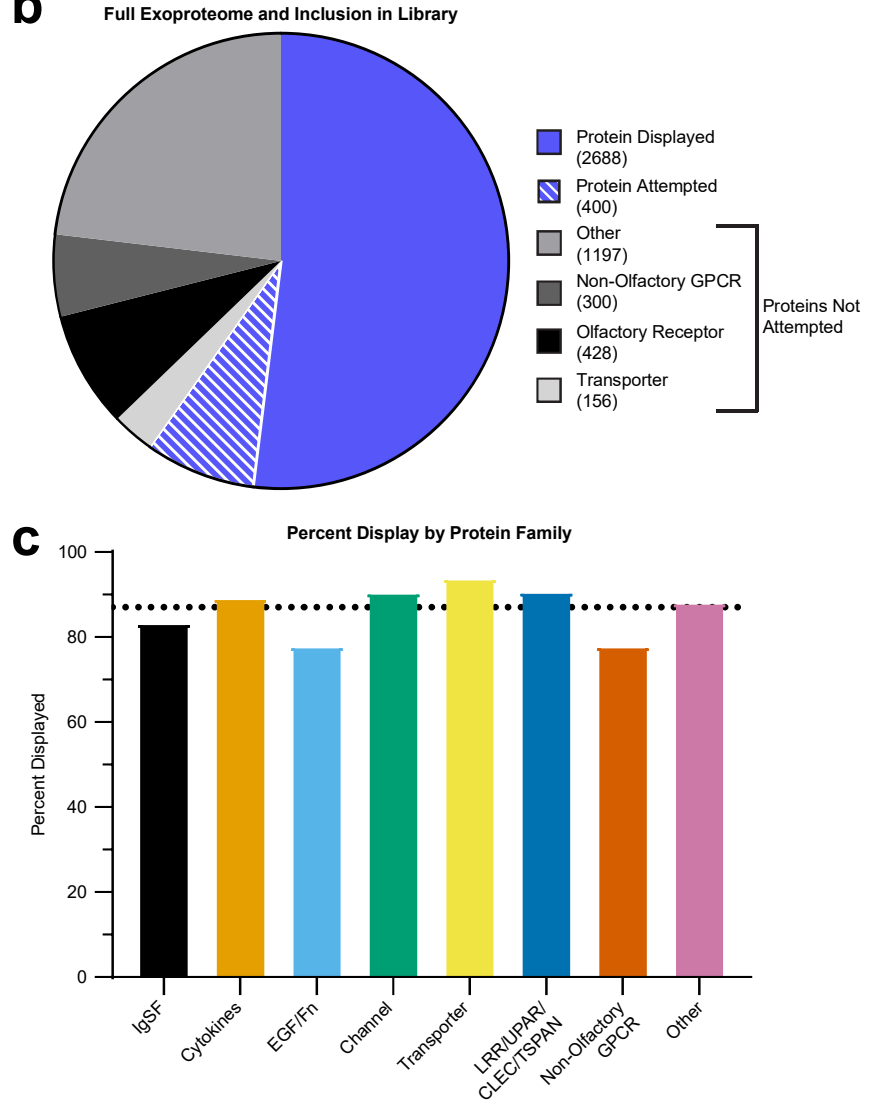

d

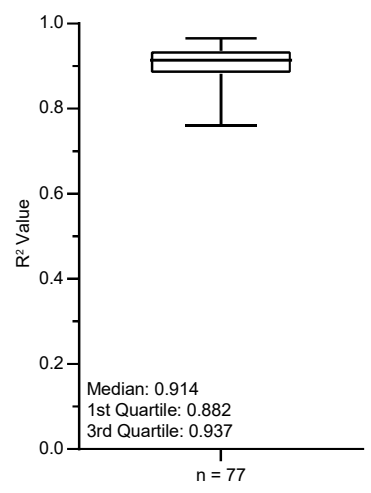

e

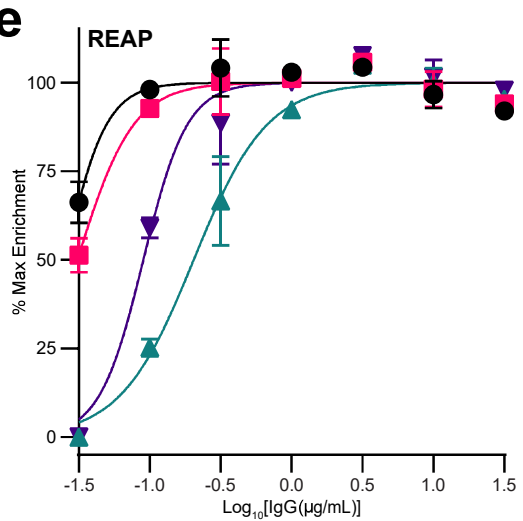

f

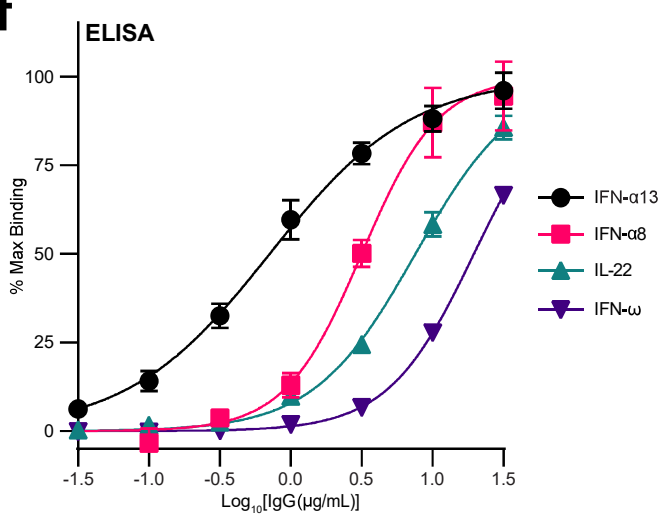

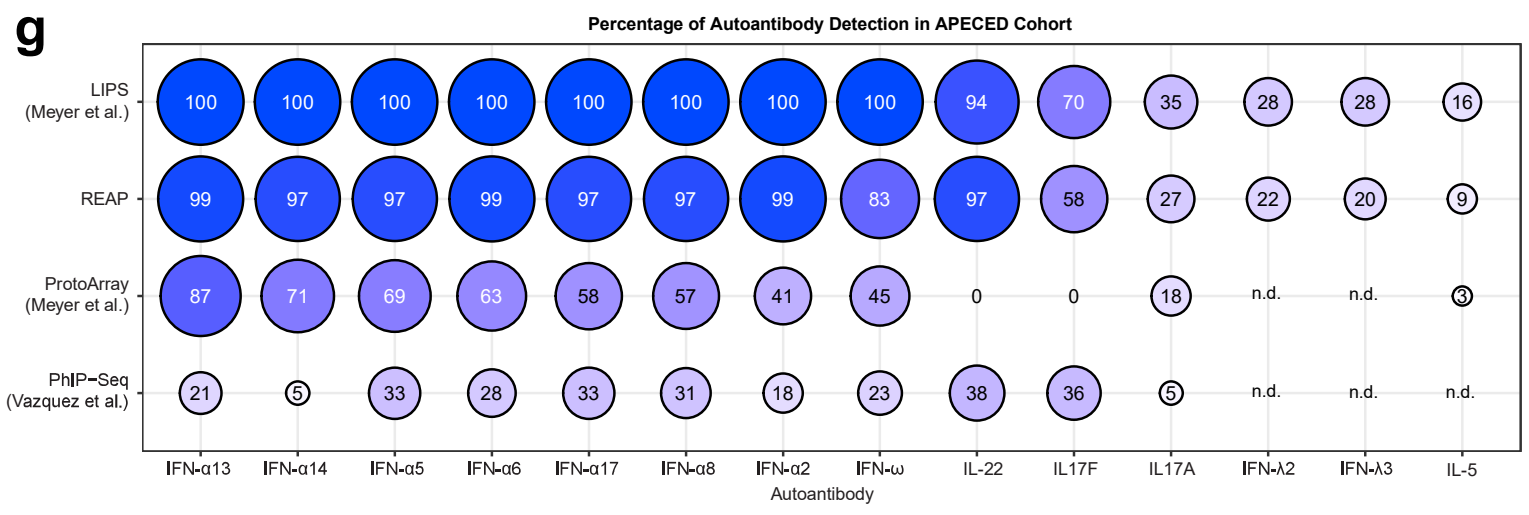


bioRxiv preprint doi: https://doi.org/10.1101/2021.02.11.430703; this version posted March 21, 2021. The copyright holder for this preprint (which was not certified by peer review) is the author/funder, who has granted bioRxiv a license to display the preprint in perpetuity. It is made available under aCC-BY-NC-ND 4.0 International license.

\section{Supplementary Figure 2}

a

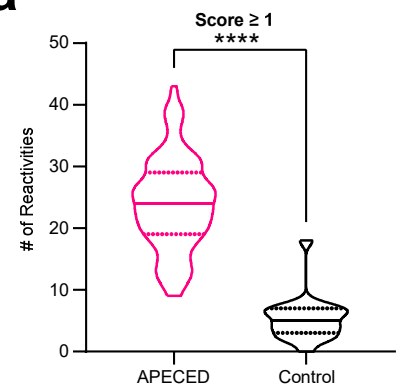

C

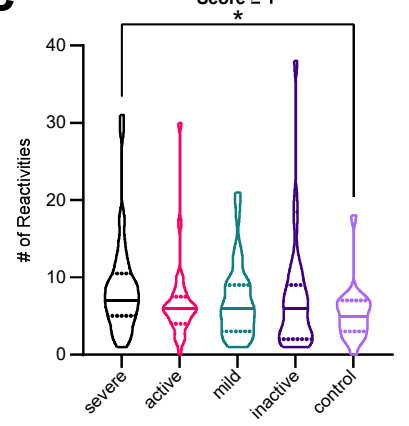

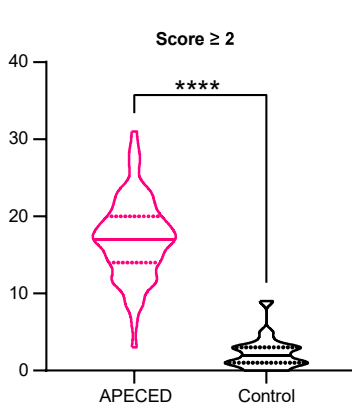

APECED

Score $\geq 2$

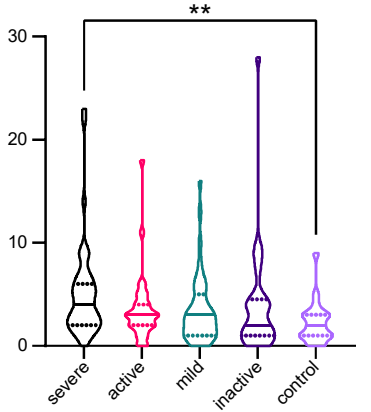

b

\begin{tabular}{|c|c|c|}
\hline & $\begin{array}{l}\text { APECED } \\
(\mathrm{n}=77)\end{array}$ & $\begin{array}{l}\text { control } \\
(\mathrm{n}=20)\end{array}$ \\
\hline score $\geq 1$ & $\begin{array}{l}24.03 \\
\star * * *\end{array}$ & 5.30 \\
\hline score $\geq 2$ & $\begin{array}{l}17.12 \\
* \star * *\end{array}$ & 2.25 \\
\hline score $\geq 3$ & $\begin{array}{l}12.95 \\
\star * * *\end{array}$ & 1.50 \\
\hline score $\geq 4$ & $\begin{array}{l}10.69 \\
* * * *\end{array}$ & 1.25 \\
\hline score $\geq 5$ & $\begin{array}{l}8.73 \\
\star \star \star \star *\end{array}$ & 0.75 \\
\hline score $\geq 6$ & $\begin{array}{l}6.29 \\
\star \star \star \star *\end{array}$ & 0.40 \\
\hline
\end{tabular}

d

Average \# of Reactivities per Sample
\begin{tabular}{|l|c|c|c|c|c|}
\hline & $\begin{array}{c}\text { severe } \\
(\mathrm{n}=\mathbf{4 5})\end{array}$ & $\begin{array}{c}\text { active } \\
(\mathrm{n}=\mathbf{3 3})\end{array}$ & $\begin{array}{c}\text { mild } \\
(\mathrm{n}=\mathbf{4 3})\end{array}$ & $\begin{array}{c}\text { inactive } \\
(\mathrm{n}=34)\end{array}$ & $\begin{array}{c}\text { control } \\
(\mathrm{n}=\mathbf{2 0})\end{array}$ \\
\hline score $\geq \mathbf{1}$ & $\begin{array}{c}8.67 \\
\star\end{array}$ & 6.67 & 6.98 & 6.97 & 5.30 \\
\hline score $\geq \mathbf{2}$ & $\begin{array}{c}5.13 \\
\star *\end{array}$ & 3.52 & 3.47 & 3.79 & 2.25 \\
\hline score $\geq \mathbf{3}$ & $\begin{array}{c}3.64 \\
\star *\end{array}$ & 2.30 & 2.51 & 2.53 & 1.50 \\
\hline score $\geq \mathbf{4}$ & 2.69 & 1.67 & 1.72 & 1.74 & 1.25 \\
\hline score $\geq \mathbf{5}$ & 1.91 & 0.91 & 1.35 & 1.06 & 0.75 \\
\hline score $\geq \mathbf{6}$ & 1.13 & 0.45 & 0.95 & 0.79 & 0.40 \\
\hline
\end{tabular}


bioRxiv preprint doi: https://doi.org/10.1101/2021.02.11.430703; this version posted March 21, 2021. The copyright holder for this preprint (which was not certified by peer review) is the author/funder, who has granted bioRxiv a license to display the preprint in perpetuity. It is made available under aCC-BY-NC-ND 4.0 International license.

\section{Supplementary Figure 3}
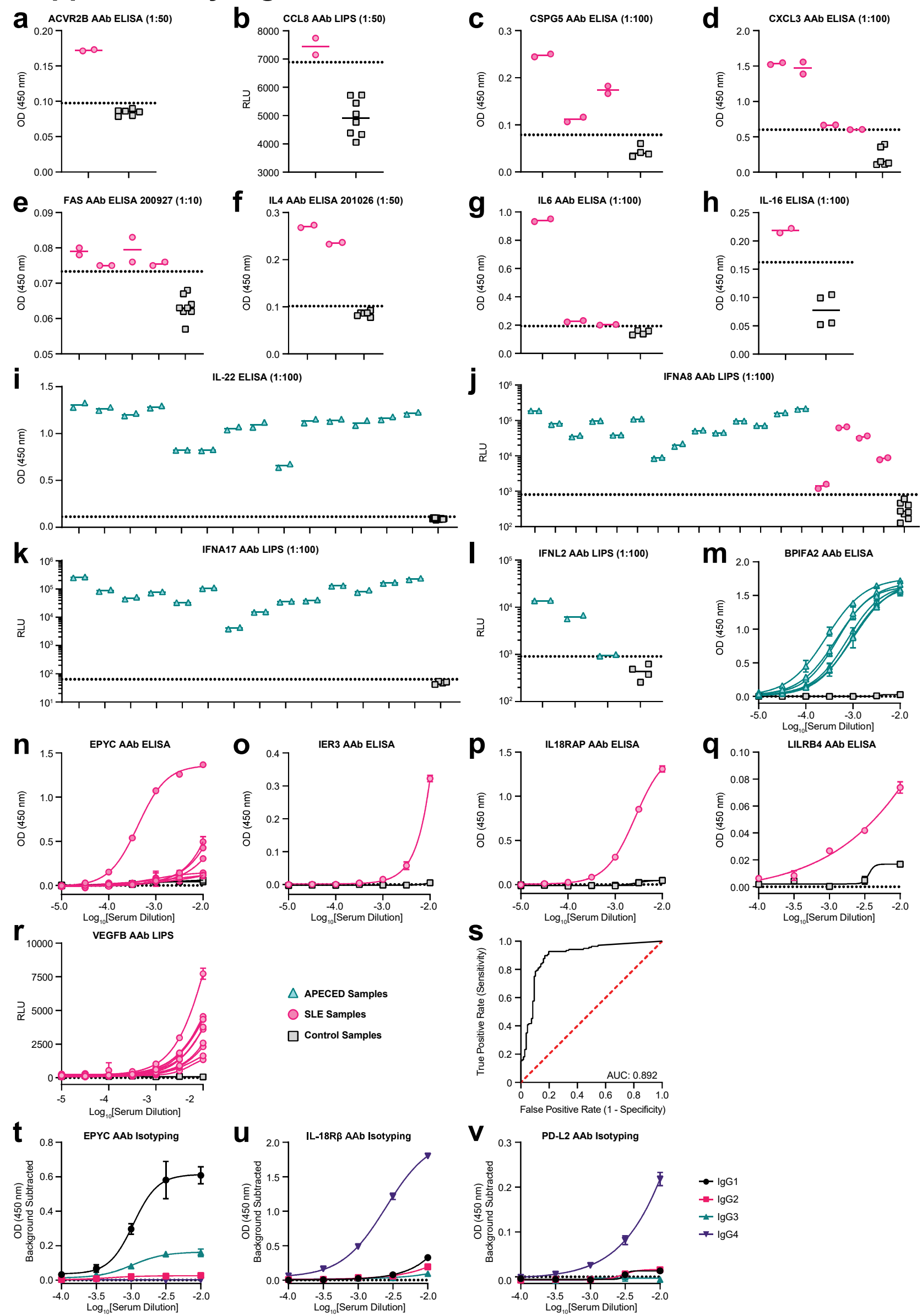

\section{$\triangle$ APECED Samples \\ O SLE Samples \\ $\square$ Control Samples}

$-\operatorname{lgG} 1$

$+\lg G 4$ 
bioRxiv preprint doi: https://doi org/10.1101/2021.0211.430703; this version posted March 21, 2021. The copyright holder for this preprint (which was not certified by peer review) is the author/funder, who has granted bioRxiv a license to display the preprint in perpetuity. It is made available under aCC-BY-NC-ND 4.0 International license.

\section{Supplementary Table 2}

Supplementary Table 2 | APECED patient demographics and clinical characteristics.

\begin{tabular}{|l|c|}
\hline \multicolumn{1}{|c|}{ APECED cohort characteristics $(\mathbf{n}=\mathbf{7 7})$} & Number $(\%)$ \\
\hline Age $^{*}$ & $24(14.4)$ \\
\hline Gender (female) & $45(58)$ \\
\hline Ethnicity & $68(88)$ \\
\hline White Non-Hispanic & $5(7)$ \\
\hline White/Hispanic & \\
\hline AlRE alleles ${ }^{* *}$ & $79(51)$ \\
\hline C.967_979del13 & $21(14)$ \\
\hline C.769C>T & \\
\hline Clinical manifestations & $66(86)$ \\
\hline Chronic mucocutaneous candidiasis & $62(81)$ \\
\hline Adrenal insufficiency & $63(82)$ \\
\hline Hypoparathyroidism & $18(23)$ \\
\hline Hypothyroidism & $26(34)$ \\
\hline Hypogonadism & $28(36)$ \\
\hline Autoimmune pneumonitis & $25(33)$ \\
\hline Autoimmune hepatitis & $53(69)$ \\
\hline Intestinal dysfunction & $1(1)$ \\
\hline Exocrine pancreatic insufficiency & $10(13)$ \\
\hline Asplenia & $26(34)$ \\
\hline Alopecia & $19(25)$ \\
\hline Vitiligo & $30(39)$ \\
\hline Sjogren's-like syndrome & $30(39)$ \\
\hline Autoimmune gastritis & $20(26)$ \\
\hline B12 deficiency & $24(31)$ \\
\hline Intrinsic factor antibody & \\
\hline Lung-targeted autoantibodies*** & \\
\hline BPIFB1 & \\
\hline KCNRG & \\
\hline $\begin{array}{l}{ }^{*} \text { Age is represented as mean (standard deviation) in years } \\
* * * \text { Data available for } 72 \text { patients } \\
\text { AIRE, autoimmune regulator; APECED, autoimmune polyendocrinopathy- } \\
\text { candidiasis-ectodermal dystrophy; BPIFB1, BPI fold containing family B member } 1\end{array}$ \\
\hline
\end{tabular}


bioRxiv preprint doi: https://doi.org/10.1101/2021.02.11.430703; this version posted March 21, 2021. The copyright holder for this preprint (which was not certified by peer review) is the author/funder, who has granted bioRxiv a license to display the preprint in perpetuity. It is made available under aCC-BY-NC-ND 4.0 International license.

\section{Supplementary Table 3}

Supplementary Table 3 | SLE patient and control demographics and clinical characteristics.

\begin{tabular}{|l|c|c|}
\hline \multicolumn{1}{|c|}{ Mean (SD) or as indicated } & $\begin{array}{c}\text { SLE Cohort } \\
\left(\mathbf{n}=\mathbf{8 5}^{*}\right)\end{array}$ & $\begin{array}{c}\text { Healthy Controls } \\
(\mathbf{n}=\mathbf{2 0})\end{array}$ \\
\hline Age, (years) & $41.7(12.6)$ & $37.2(11)$ \\
\hline Gender, N (\% female) & $76(89.4)$ & $12(60)$ \\
\hline Ethnicity, N (\%) & $22(26)$ & $3(15)$ \\
\hline Hispanic & $35(41)$ & $8(40)$ \\
\hline Non-Hispanic & $28(33)$ & $9(45)$ \\
\hline African American & & \\
\hline Clinical Manifestations, N (\%) & $40(47.1)$ & \\
\hline Skin & $16(18.8)$ & \\
\hline Mucocutaneous & $29(34.1)$ & \\
\hline Musculoskeletal & $20(23.5)$ & \\
\hline Renal & $4(4.7)$ & \\
\hline Cardiorespiratory & $7(8.2)$ & \\
\hline Hematological & $0(0)$ & \\
\hline Neuropsychiatric & & \\
\hline Serologies, N (\%) & $40(47.1)$ & \\
\hline Positive dsDNA & $34(40)$ & \\
\hline Low complement & $6.3(6.1)$ & \\
\hline SLEDAl score & & \\
\hline Medications, any use N (\%) & $40(47.1)$ & \\
\hline Prednisone & $72(84.7)$ & \\
\hline Hydroxychloroquine & $24(28.2)$ & \\
\hline Mycophenolate mofetil & $6(7.1)$ & \\
\hline Methotrexate & $6(7.7)$ & \\
\hline Azathioprine & & \\
\hline Belimumab & & \\
\hline $\begin{array}{l}\text { Others (cyclophosphamide, } \\
\text { rituximab, tacrolimus, infliximab, etc.) }\end{array}$ & & \\
\hline $\begin{array}{l}\text { Abbreviations: SLEDAl (Systemic Lupus Erythematosus Disease Activity Index). } \\
\text { Prednisone dosing ranges from 5 mg daily to 60 mg daily. } \\
\text { *Complete clinical data was not available for a subset of patients. A total of 106 patients } \\
\text { were screened. }\end{array}$ & \\
\hline
\end{tabular}

